\title{
Properties Important to Mixing for WTP Large Scale Integrated Testing
}

\author{
D. C. Koopman \\ C. J. Martino \\ M. R. Poirier
}

April 2012

Savannah River National Laboratory Savannah River Nuclear Solutions, LLC Aiken, SC 29808

Prepared for the U.S. Department of Energy under contract number DE-AC09-08SR22470. 
SRNL-STI-2012-00062

Revision 0

\section{DISCLAIMER}

This work was prepared under an agreement with and funded by the U.S. Government. Neither the U.S. Government or its employees, nor any of its contractors, subcontractors or their employees, makes any express or implied:

1. warranty or assumes any legal liability for the accuracy, completeness, or for the use or results of such use of any information, product, or process disclosed; or

2. representation that such use or results of such use would not infringe privately owned rights; or

3. endorsement or recommendation of any specifically identified commercial product, process, or service.

Any views and opinions of authors expressed in this work do not necessarily state or reflect those of the United States Government, or its contractors, or subcontractors.

\section{Printed in the United States of America \\ Prepared for \\ U.S. Department of Energy}


Keywords: Hanford, WTP, Mixing, Pulse Jet Mixer

Retention: Permanent

\title{
Properties Important to Mixing for WTP Large Scale Integrated Testing
}

\author{
D. C. Koopman \\ C. J. Martino \\ M. R. Poirier
}

April 2012

Savannah River National Laboratory Savannah River Nuclear Solutions, LLC Aiken, SC 29808

Prepared for the U.S. Department of Energy under contract number DE-AC09-08SR22470. 


\section{REVIEWS AND APPROVALS}

\section{AUTHORS:}

D. C. Koopman, SRNL Process Technology Programs APPROVALS:

F. M. Pennebaker, Manager 


\section{EXECUTIVE SUMMARY}

Large Scale Integrated Testing (LSIT) is being planned by Bechtel National, Inc. to address uncertainties in the full scale mixing performance of the Hanford Waste Treatment and Immobilization Plant (WTP). Testing will use simulated waste rather than actual Hanford waste. Therefore, the use of suitable simulants is critical to achieving the goals of the test program. External review boards have raised questions regarding the overall representativeness of simulants used in previous mixing tests. Accordingly, WTP requested the Savannah River National Laboratory (SRNL) to assist with development of simulants for use in LSIT. Among the first tasks assigned to SRNL was to develop a list of waste properties that matter to pulse-jet mixer (PJM) mixing of WTP tanks.

This report satisfies Commitment 5.2.3.1 of the Department of Energy Implementation Plan for Defense Nuclear Facilities Safety Board Recommendation 2010-2: physical properties important to mixing and scaling. In support of waste simulant development, the following two objectives are the focus of this report:

- Assess physical and chemical properties important to the testing and development of mixing scaling relationships.

- Identify the governing properties and associated ranges for LSIT to achieve the Newtonian and non-Newtonian test objectives. This includes the properties to support testing of sampling and heel management systems.

The test objectives for LSIT relate to transfer and pump out of solid particles, prototypic integrated operations, sparger operation, PJM controllability, vessel level/density measurement accuracy, sampling, heel management, PJM restart, design and safety margin, Computational Fluid Dynamics (CFD) Verification and Validation (V\&V) and comparison, performance testing and scaling, and high temperature operation. The slurry properties that are most important to Performance Testing and Scaling depend on the test objective and rheological classification of the slurry (i.e., Newtonian or non-Newtonian).

The most important properties for testing with Newtonian slurries are the Archimedes number distribution and the particle concentration. For some test objectives, the shear strength is important. In the testing to collect data for CFD V\&V and CFD comparison, the liquid density and liquid viscosity are important. In the high temperature testing, the liquid density and liquid viscosity are important. The Archimedes number distribution combines effects of particle size distribution, solid-liquid density difference, and kinematic viscosity.

The most important properties for testing with non-Newtonian slurries are the slurry yield stress, the slurry consistency, and the shear strength. The solid-liquid density difference and the particle size are also important. It is also important to match multiple properties within the same simulant to achieve behavior representative of the waste.

Other properties such as particle shape, concentration, surface charge, and size distribution breadth, as well as slurry cohesiveness and adhesiveness, liquid $\mathrm{pH}$ and ionic strength also influence the simulant properties either directly or through other physical properties such as yield stress. 
The implementation plan includes a list of characteristics that would challenge the PJM mixing and transfer systems and indicates that the assessment of simulants would include one or more of the challenging characteristics. The recommendations for properties to be adjusted during Limits of Performance testing, as related to the list of challenging characteristics, are as follows:

- Proportion of irregularly shaped particles and the degree of irregularity

Recommended. Simulants should continue to include a variety of particle shapes. Spherical particles should be considered for at least a portion of the particles at the high end of the Archimedes distribution. A spike of flat or elongated shapes could be introduced into a baseline simulant mixture in incrementally larger proportions.

- Progressively larger particles

Recommended. For Newtonian vessels and low yield stress fluids in non-Newtonian vessels, particle size should be increased to identify the limits of performance for bottom motion/accumulation, transfer/pump out, and sampling. Heel management tests should also involve increasing the particle size.

- Progressively denser particles

Not recommended to extend beyond Performance Testing and Scaling simulant range. Simulants with a range of selected densities within the range reasonable for actual waste would be adequate for bounding the effect of increasing the particle-liquid density difference through analogous increases in particle size.

- Progressively higher shear strength of settled layers

Recommended. Testing to support PJM restart and heel management should involve increasing the shear strength of settled beds of solids to beyond the range covered by the Performance Testing and Scaling simulants.

- Progressively lower and higher yield stress and consistency for non-Newtonian simulants Recommended. Limits of performance in non-Newtonian vessels should be explored both with simulants that have less than $6 \mathrm{~Pa}$ yield stress (at $1 \mathrm{cP}$ consistency) and with simulants that have greater than $30 \mathrm{~Pa}$ yield stress and $30 \mathrm{cP}$ consistency. Limits of performance in Newtonian vessels should be explored with simulants that have greater than 1 Pa yield stress.

- Progressively higher solids loading

Recommended for Newtonian mixing and heel management cases, but not recommended for non-Newtonian case beyond influence on yield stress and consistency. Heel management tests should also test increasing the quantity of settled solids in the heel.

- Progressive variation in the degree of thixotropic and rheopectic properties

Not recommended. Some of the flow curves for material in the M-12 program showed degrees of hysteresis. As acknowledged by the authors of the M-12 reports, factors other than thixotropic or rheopectic behavior could explain the hysteresis, including solids settling out of the measurement gap, evaporation of water during measurements, and sample degassing during measurements. The magnitude of the observed hysteresis was not large enough to be significant to WTP. 


\section{TABLE OF CONTENTS}

1.0 Introduction 1

1.1 Hanford WTP Background . 1

1.2 Hanford Waste Background. 2

1.3 Large Scale Integrated Testing 2

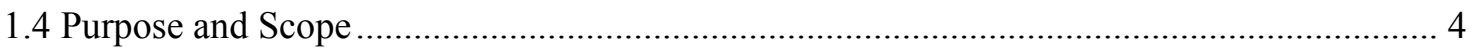

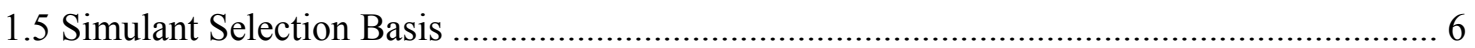

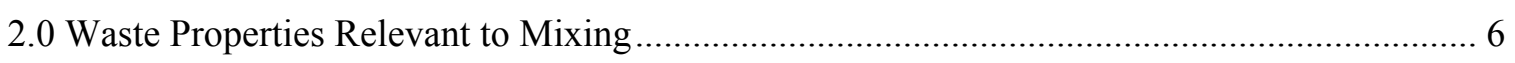

2.1 Properties with a Well Established Influence on Mixing ................................................... 7

2.1.1 Particle Size and Particle Density Distribution .............................................................. 7

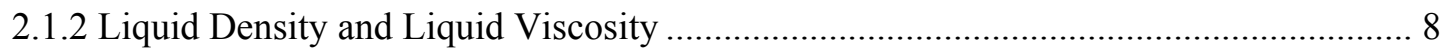

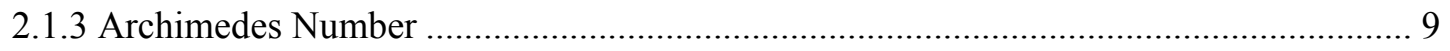

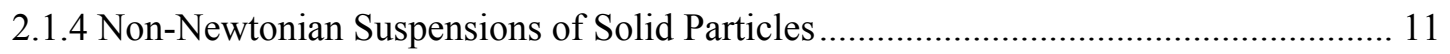

2.1.5 Properties for Beds of Settled Particles ..................................................................... 12

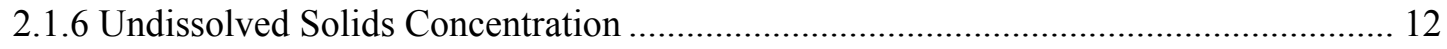

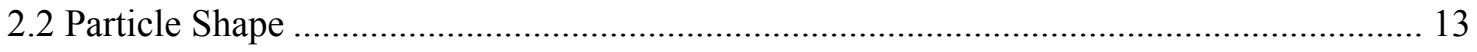

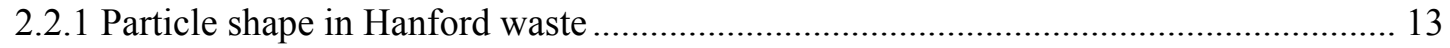

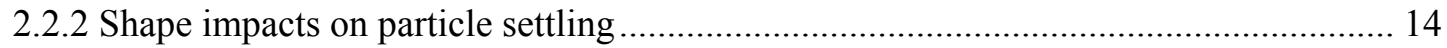

2.2.3 Shape impacts on particle suspension and bed erosion .............................................. 15

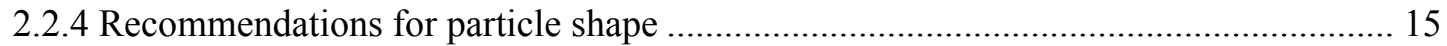

2.3 Time Dependent (Thixotropic/Rheopectic) Rheological Phenomena ................................ 16

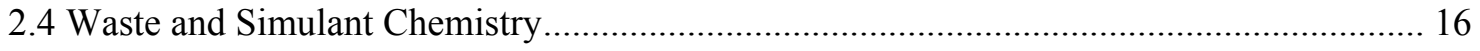

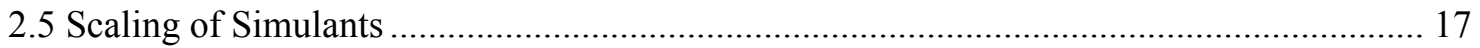

3.0 Recommendations for Simulant Properties to Meet Test Objectives ..................................... 18

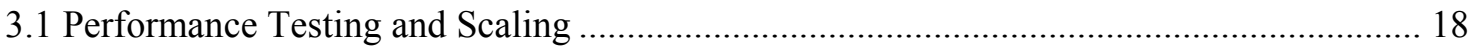

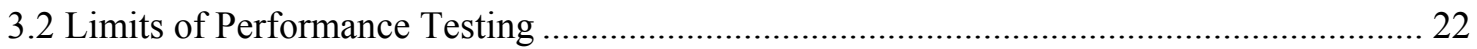

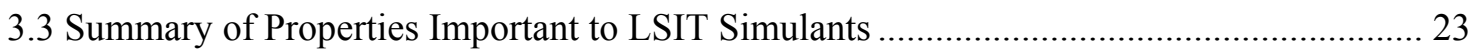

3.4 Recommendations on Chemical versus Physical Simulants............................................... 25

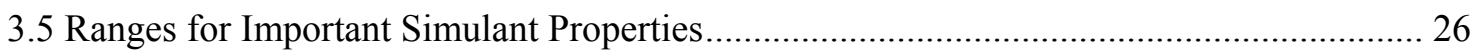

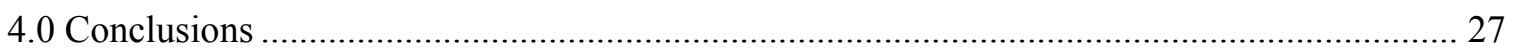

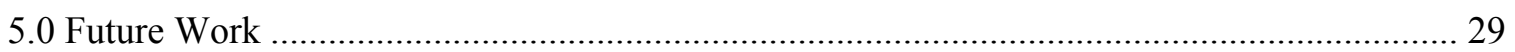

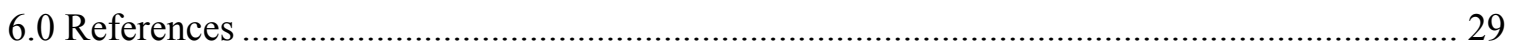

A. Appendix A: Waste Chemistry and Chemistry of Simulants ……................................... 33

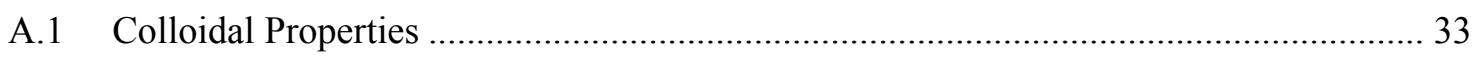




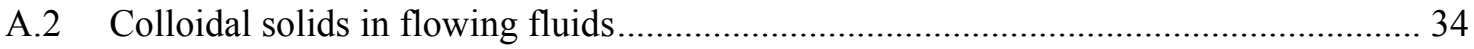

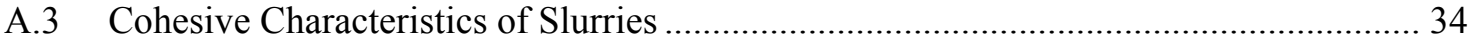

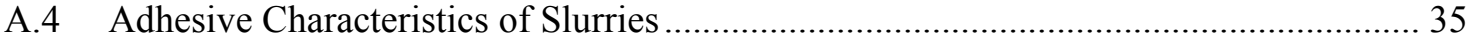

A.5 Foaming, air entrainment, and gas retention (effects of biphylic particles)................... 35

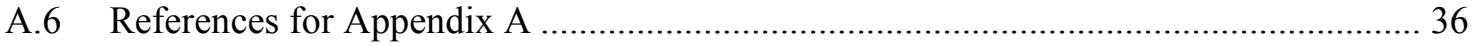




\section{LIST OF TABLES}

Table 1: Planned LSIT Program (adapted from Ref. 2) ........................................................... 4

Table 2: Properties important for LSIT with Newtonian Slurries .............................................. 24

Table 3: Properties important for LSIT with non-Newtonian Slurries........................................ 24

Table 4: Summary of simulant property ranges recommended for LSIT ................................... 27 


\section{LIST OF ABBREVIATIONS}

$\begin{array}{ll}\text { BNI } & \text { Bechtel National, Inc. } \\ \text { CFD } & \text { Computational Fluid Dynamics } \\ \text { DNFSB } & \text { Defense Nuclear Facilities Safety Board } \\ \text { DOE } & \text { Department of Energy } \\ \text { DWPF } & \text { Defense Waste Processing Facility } \\ \text { ECR } & \text { Effective Clearing Radius } \\ \text { HLP } & \text { HLW Lag Storage and Feed Blending Process } \\ \text { HLW } & \text { High Level Waste } \\ \text { ICD } & \text { Interface Control Document } \\ \text { i.e.p. } & \text { Isolelectric Point } \\ \text { IP } & \text { Implementation Plan } \\ \text { LAW } & \text { Low Activity Waste } \\ \text { LSIT } & \text { Large Scale Integrated Testing } \\ \text { PEP } & \text { Pretreatment Engineering Platform } \\ \text { PJM } & \text { Pulse Jet Mixer } \\ \text { PNNL } & \text { Pacific Northwest National Laboratory } \\ \text { PSD } & \text { Particle Size Distribution } \\ \text { PSDD } & \text { Particle Size and Density Distribution } \\ \text { PTF } & \text { Pretreatment Facility } \\ \text { SRNL } & \text { Savannah River National Laboratory } \\ \text { SRS } & \text { Savannah River Site } \\ \text { TOC } & \text { Tank Operations Contractor } \\ \text { UDS } & \text { Undissolved Solids } \\ \text { UFP } & \text { Ultrafiltration Process } \\ \text { V\&V } & \text { Verify and Validate } \\ \text { WTP } & \text { Waste Treatment and Immobilization Plant } \\ & \end{array}$




\section{LIST OF SYMBOLS}

$a$

$\mathrm{Ar}$

b

$c$

C

$d_{S}$

$d_{P}$

g

$n$

$\mathrm{Re}_{\mathrm{P}}$

$S_{F}$

$V_{S}$

$\dot{\gamma}$

$\eta$

$v_{L}$

$\mu_{L}$

$\rho$

$\rho_{L}$

$\rho_{S}$

$\tau$

$\tau_{Y S}$

longest particle dimension in Corey's shape factor

particle Archimedes number

intermediate particle dimension in Corey's shape factor

shortest particle dimension in Corey's shape factor

settling regime constant for $\mathrm{Re}_{\mathrm{P}}$ to Ar relationship

particle diameter based on a sphere of equal volume

particle diameter

gravitational acceleration

settling regime constant for $\mathrm{Re}_{\mathrm{P}}$ to Ar relationship

particle Reynolds number

Corey's shape factor

terminal settling velocity

shear rate

Bingham consistency

liquid kinematic viscosity

liquid viscosity

density

liquid density

particle density

shear stress

Bingham yield stress 


\subsection{Introduction}

In December 2010, the Defense Nuclear Facilities Safety Board (DNFSB) issued a recommendation that voiced the following potential safety concerns related to the Pulse Jet Mixer (PJM) and transfer systems of the Hanford Waste Treatment and Immobilization Plant (WTP): ${ }^{1}$

- Accumulation of fissile material at the bottom of vessels leading to potential criticality.

- Generation and accumulation of hydrogen resulting from the accumulation of solids.

- The possibility that accumulating solids will interfere with the vessel-level detection system leading to loss of PJM control and overblows.

The DNFSB recommended in part that the U. S. Department of Energy (DOE) undertake large scale testing to address uncertainties in full-scale PJM performance that could lead to safety concerns. Bechtel National, Inc. (BNI) and DOE committed to undertake such a program to address the uncertainties and increase confidence. ${ }^{2}$ In November 2011, the DOE issued an Implementation Plan (IP) agreeing to address the DNFSB's concerns. ${ }^{3}$

This document summarizes the properties that matter for simulants used to evaluate mixing in the Large Scale Integrated Testing (LSIT) of WTP. Property ranges are identified for the Performance Testing and Scaling and Limits of Performance phases of the test program.

\subsection{Hanford WTP Background}

BNI is designing and constructing the WTP at the Hanford Site in order to pretreat and vitrify waste stored in 177 single- and double-shell underground waste storage tanks. The WTP will consist of three primary processing facilities: a pretreatment facility (PTF), a low-activity waste (LAW) vitrification facility, and a high-level waste (HLW) vitrification facility. The PTF will receive waste feed from the Hanford tank farms and will separate it into:

1) a high-volume, low-activity, liquid process stream stripped of most solids and radioisotopes, and

2) a much smaller-volume HLW slurry containing the solids and most of the radioactivity, along with minimal soluble salt.

In the PTF, solids and radioisotopes will be removed from the waste received from the tank farms by precipitation, filtration, and ion exchange processes, producing the LAW stream. The washed, concentrated slurry will be blended with the ion exchange eluent streams containing soluble radioisotopes to produce the HLW stream. The HLW and LAW vitrification facilities will receive these streams from the PTF for conversion into molten glass, which will be poured directly into stainless steel canisters for long-term interim storage.

Numerous vessels are used to process the LAW and HLW streams, many of which employ PJM technology for mixing. The non-Newtonian vessels also include air sparging systems. These technologies have been selected for use in black cells in WTP. Because of the high radiation in the black cells, the maintenance of the vessels and components inside the cells is not feasible for 
the operating life of the WTP. PJM and air-sparger technologies were selected for use in the black cells because they lack moving mechanical parts that would require maintenance.

PJM technology will be used in the WTP for slurry mixing applications requiring solids suspension and solids mixing, as well as for fluid blending and release of hydrogen gas. The PJMs operate in different modes. The suction phase draws process fluid into the pulse jet tube from the vessel. The drive phase pressurizes the PJM tubes with compressed air, discharging the fluid at high velocity back into the vessel causing mixing to occur. The drive phase is followed by a vent phase, which allows for depressurization of the PJM by venting air into the pulse jet vent system. These three phases (suction, drive, and vent) make up the PJM cycle. The combined suction, drive, and vent cycle time for the major slurry processing vessels is approximately three minutes, and is performed continually in normal operations. Planned operation of the PJMs in the WTP is in the continuous pulsing mode. In PJM-mixed vessels, solids will tend to settle between PJM drive phases. ${ }^{4}$

\subsection{Hanford Waste Background}

In assessing the data related to property ranges relevant to mixing operations within WTP, Pacific Northwest National Laboratory (PNNL) developed an overview report on the Hanford waste physical and rheological properties. ${ }^{5}$ The overview compiled and updated data from previous overviews and studies (for example from Refs. 6,7, and 8) and discussed the data gaps. The review ranked the most important waste properties based on the importance of parameters in selected engineering design correlations. The properties were ranked in importance based on the functionality exclusive of the property range in waste. Some of the rankings gave a high importance for properties that vary over a very narrow range in WTP, such as liquid density. Properties that vary over a narrow range are unlikely to be the most important properties with respect to mixing, regardless of the relatively high sensitivity of the parameters in the correlations.

The PNNL review predominantly reflected characterization information for the as-stored waste because that is the source of most of the available sampling data. This limitation must be considered in the application of currently available tank characterization data to simulant development for WTP mixing system test programs. Waste retrieval will influence some of the properties of the waste (for example, by breaking-up layers, dissolving salts, and reducing agglomerated particle sizes) and WTP processing will influence some of the properties important to mixing. ${ }^{9}$ The effects of retrieval and processing on waste properties, such as from caustic leaching for aluminum removal and from filtration for slurry concentration, needs to be considered in the development of simulants for testing these process steps.

\subsection{Large Scale Integrated Testing}

Some key aspects of PJM-mixed vessel operation were not fully evaluated in previous small scale testing programs. Full-scale PJM-mixed vessel performance will differ from the scaled tests performed to date. To address the uncertainties from problems of scale, integrated testing at large scale will be completed prior to cold commissioning to increase confidence in projected full-scale vessel mixing performance and operation. This testing will evaluate PJM control strategies with prototypic operating conditions and controls; the full range of vessel fill conditions; process sampling; and the suction line transfer system. ${ }^{2}$ 
Three categories of testing will be performed: Computational Fluid Dynamics (CFD) Verification and Validation (V\&V), Performance Testing and Scaling (i.e., confirmation of mixing performance scaling), and Limits of Performance testing. The CFD V\&V testing and Performance Testing and Scaling will be performed with waste simulants that have physical properties covering the ranges that the WTP vessels and transfer systems have been designed to handle, such as those identified in the Basis of Design ${ }^{10}$ and the Interface Control Document (ICD) $19 .{ }^{11}$ Limits of Performance testing will use waste simulants with physical properties that are systematically adjusted in a manner to challenge the PJM mixing effectiveness. The intent of Limits of Performance testing is to define the envelope of waste physical properties that are consistent with the requirements for acceptable mixing for the various LSIT test objectives by probing the edge of the operability envelope to failure.

Specific LSIT test objectives (see Table 1) will be probed to assure that the design basis is acceptable, and updated scaling relationships will be derived through testing in up to four different test platforms. A 14-foot diameter test platform will be used for testing to support vessel operation and control. The 14-foot diameter platform and smaller platforms (nominal 8foot diameter and 4-foot diameter platforms) will be used for testing to support design verification. A single PJM test platform will be constructed to demonstrate the functionality and control of a single large-scale pulse jet tube similar to those intended to be deployed into the largest PTF vessels. 
Table 1: Planned LSIT Program (adapted from Ref. 2)

\begin{tabular}{|l|c|c|c|c|}
\hline $\begin{array}{l}\text { Test Objective } \\
\text { Categories }\end{array}$ & $\begin{array}{c}\text { 4-foot Diameter } \\
\text { Test Platform }\end{array}$ & $\begin{array}{c}\text { 8-foot Diameter } \\
\text { Test Platform }\end{array}$ & $\begin{array}{c}\text { 14-foot Diameter } \\
\text { Test Platform }\end{array}$ & $\begin{array}{c}\text { Single PJM } \\
\text { Test Platform }\end{array}$ \\
\hline PJM Controllability & & & $\mathrm{X}$ & $\mathrm{X}$ \\
\hline $\begin{array}{l}\text { Vessel Level/Density } \\
\text { Instrument Accuracy }\end{array}$ & & $\mathrm{X}$ & $\mathrm{X}$ & $\mathrm{X}$ \\
\hline Sampling Capability & $\mathrm{X}$ & $\mathrm{X}$ & $\mathrm{X}$ & \\
\hline Transfer/Pump Out & $\mathrm{X}$ & $\mathrm{X}$ & $\mathrm{X}$ & \\
\hline Heel Management & $\mathrm{X}$ & $\mathrm{X}$ & $\mathrm{X}$ & \\
\hline $\begin{array}{l}\text { Prototypic Integrated } \\
\text { Operation }\end{array}$ & & $\mathrm{X}$ & $\mathrm{X}$ & \\
\hline $\begin{array}{l}\text { Performance Testing and } \\
\text { Scaling }\end{array}$ & $\mathrm{X}$ & $\mathrm{X}$ & $\mathrm{X}$ & \\
\hline $\begin{array}{l}\text { Integrated Vessel } \\
\text { Sparger Operation }\end{array}$ & $\mathrm{X}$ & $\mathrm{X}$ & $\mathrm{X}$ & \\
\hline $\begin{array}{l}\text { Design \& Safety Margin } \\
\text { for Mixing to Support } \\
\text { Safety Functions }\end{array}$ & $\mathrm{X}$ & & & \\
\hline PJM Restart & & & & \\
\hline $\begin{array}{l}\text { CFD Comparison and } \\
\text { Validation }\end{array}$ & & & & \\
\hline $\begin{array}{l}\text { High Temperature } \\
\text { Operation }\end{array}$ & & & & \\
\hline
\end{tabular}

\section{$1.4 \underline{\text { Purpose and Scope }}$}

This report satisfies IP Commitment 5.2.3.1, physical properties important to mixing and scaling. ${ }^{3}$ In support of waste simulant development, the following two objectives are the focus of this report:

- Assess physical and chemical properties important to the testing and development of mixing scaling relationships.

- Identify the governing properties and associated ranges for LSIT to achieve the Newtonian and non-Newtonian test objectives.

This document identifies the required characteristics for test simulants needed to perform the program scope listed in Table 1. This includes the properties to support testing of sampling and heel management systems. 
The DOE Implementation Plan for DNFSB Recommendation 2010-2 proposed a non-inclusive list of simulant properties that should be adjusted to challenge the PJM mixing and transfer system during Limits of Performance testing: ${ }^{3}$

- Proportion of irregularly shaped particles and the degree of irregularity

- Progressively larger particles

- Progressively denser particles

- Progressively higher shear strength of settled layers

- Progressively lower and higher yield stress and consistency for non-Newtonian simulants

- Progressively higher solids loading

- Progressive variation in the degree of thixotropic and rheopectic properties

The physical and chemical properties of Hanford waste applicable to LSIT are reviewed in Section 2 of this report. Recommended simulant properties for LSIT testing for both Newtonian and non-Newtonian conditions applicable to WTP are summarized in Section 3. The analysis considered the properties and property groupings listed below in order to better address the needs of the test program. Though not all properties are independent, they were considered and evaluated for their relative importance to mixing and related LSIT objectives:

- Particle size

- Particle size distribution (PSD)

- Particle density

- Particle size and density distribution (PSDD)

- Particle shape

- Liquid phase density

- Particle-liquid density difference

- Liquid phase viscosity

- Archimedes number distribution

- Undissolved solids (UDS) mass and/or volume fraction

- Slurry rheological properties

- Slurry thixotropic and rheopectic behavior

- Shear strength of settled waste

- Critical shear stress for erosion

- Slurry cohesiveness

- Slurry adhesiveness

- Liquid phase $\mathrm{pH}$

- Liquid phase ionic strength

- Particle isoelectric points (i.e.p.)

- Particle zeta potentials

- Foam formation, air entrainment and gas retention

Some of the properties listed above are affected by operating and test parameters such as time and temperature. Some of the properties are not well characterized for Hanford waste, but the fact that data are not available for a property does not reduce its potential significance to mixing. There are methods for preparing simulants with similar properties to actual waste based on first principles. The basis for deciding which simulants can be physical simulants and which may need to be chemical simulants was also evaluated. The analysis considered conditions both prior to and after the caustic leaching step in PTF operations in order address potential changes in 
waste properties. This report provides technical justification for a set of simulant properties to be tested over an extended range during Limits of Performance testing.

This document covers the properties that pertain to the appropriate mixing requirements from "Determination of Mixing Requirements for PJM-Mixed Vessels in WTP.",

An additional property, particle/slurry abrasiveness, was considered as a potential simulant property, but is not included in this document because it falls outside of the scope for the LSIT test program.

\subsection{Simulant Selection Basis}

Simulant development, verification, validation, and documentation are governed by a WTP simulant development guide. ${ }^{13}$ The guide outlines five sequential steps to assure that a simulant is relevant to the test objectives:

1. Define Scope for Simulant Use

2. Specify Simulant Requirements (chemical composition, physical and rheological properties)

3. Design Simulant and Specify Preparation Procedure

4. Verify and Validate Simulant Meets Requirements

5. Finalize Simulant Design Documentation

For the analysis, References 2 and 3 provide the key input to the first step: define scope for simulant use. This document begins to address the second step: specify simulant requirements. Completion of the second step will occur as part of IP Commitment 5.2.3.2, since the IP requires that detailed simulant requirements be based on test plans (IP Commitments 5.1.3.6, 5.4.3.6, and 5.6.3.6) which have yet to be prepared.

This document pertains to waste and simulant properties and ranges for PJM testing, and specifically for LSIT (IP Commitment 5.2.3.1). A separate task has been performed by the Tank Operations Contractor (TOC) that pertains to Waste Feed Delivery Mixing and Sampling Program Simulant Definition for Tank Farm Performance Testing (IP Commitment 5.5.3.5). ${ }^{14}$ Because these tasks intersect at the interface between the waste that is staged by the TOC and received by WTP, there has been collaborative review of these two commitments.

\subsection{Waste Properties Relevant to Mixing}

Section 2 outlines properties that can potentially influence PJM-mixed vessel performance. Expected property ranges are described, and the relative impacts of the properties on mixing performance are discussed. A number of the properties considered in this section have well established significance for mixing and transfer operations based on previous analyses and Hanford-related testing. For these properties, the analysis primarily provides an estimation of the relative influence of each property on PJM mixing and defines the expected WTP ranges. The other properties considered are discussed in more or less detail depending on the likelihood of their impact on mixing and transfer operations. 


\subsection{Properties with a Well Established Influence on Mixing}

The importance of a number of properties for WTP mixing is well established and these properties are given only brief treatment in this document:

- Particle size and PSD

- Particle density and PSDD

- Liquid density

- Liquid viscosity

- Non-Newtonian slurry rheology

- Undissolved solids concentration

- Properties for settled beds of solids

\subsubsection{Particle Size and Particle Density Distribution}

Hanford waste particles come in a wide range of sizes and densities, and this impacts how these particles behave when suspended in a liquid or settled on the vessel floor. Both particle size, $d_{P}$, and particle density, $\rho_{S}$, appear in numerous correlations describing particle suspension and settling behavior. Analytical PSDs have been generated for some waste samples subject to the limitations of the instrumentation and assumptions about the relationship between the shape of a particle and its mean diameter. Mean particle density can be derived from the ratio of the particle mass fraction and volume fraction. A PSDD can be calculated from an estimate of the solid phases present in the particles, their inherent density, and the degree of agglomeration. Calculations of this type have been performed for a number of waste samples for different assumed degrees of agglomeration. ${ }^{5}$ These PSDD calculations can be shown to be consistent with overall waste characteristics, but a limited number of large waste particles have also been found that are inconsistent with the corresponding PSDD calculations. ${ }^{18}$

Fast settling particles are a potential concern to PJM-mixed vessels in WTP. The periodic nature of the PJM drive phase creates periods when settling can be the dominant phenomenon, especially in Newtonian slurry vessels. Fast settling particles need to be represented in LSIT simulants. The particle size distribution impacts particle packing density and thus should affect the settled layer shear strength and critical shear stress for erosion.

Certain particles are of greater interest due to safety related concerns such as criticality. Plutonium compounds in most of the waste tanks were formed from co-precipitation of plutonium with neutron absorbing isotopes of other elements. This is not the case for wastes from the Plutonium Finishing Plant that are contained in several tanks. ${ }^{15}$ Due to the potential impact of this material on criticality safety, the behavior of particles similar to the non-coprecipitated $\mathrm{Pu}$ should be included in the simulants used during LSIT.

The washing and caustic leaching operations of PTF are expected to change PSD and PSDD. During testing of caustic leaching and washing of actual waste composites, order of magnitude reductions in particle size were observed for two of the five feeds. ${ }^{9}$ Dissolution and crossflow filtration tend to break down agglomerates into smaller pieces. Caustic leaching tends to dissolve compounds of aluminum and sodium preferentially, which are among the lower density species in the waste solids. Thus, there also tends to be an associated change in the average particle density toward more dense particles, since the dissolved species are primarily below the average solid 
density. For example, caustic leaching of high iron solids was shown to increase the average particle density from $2.9 \mathrm{~g} / \mathrm{mL}$ to about $3.8 \mathrm{~g} / \mathrm{mL}$.

Salt particles are included in the definition of what makes up UDS in the Hanford tank farm. Salt particles may have relatively large sizes and a variety of crystal shapes. ${ }^{16}$ The salts tend to be the more soluble components of the waste at the conditions encountered in the PTF. Complete dissolution is not expected for some salt components during mobilization in the tank farm. Including salt particle information in the slurry PSDD analyses is not as important as including particle information for less-water-soluble UDS.

The following are the recommendations for ranges of particle size and density. The Performance Testing and Scaling should use particles with a size range of $0.2-700 \mu \mathrm{m} .{ }^{5,10}$ Particles as large as $1441 \mu \mathrm{m}$ have been measured for sludge. ${ }^{5}$ The range of particle densities is $2.2-11.4 \mathrm{~g} / \mathrm{mL}$ based on assumed primary particle density. ${ }^{5}$ If plutonium metal is present, particle density would be as high as $19 \mathrm{~g} / \mathrm{mL}$. These recommendations are consistent with those made for related TOC simulants. ${ }^{14}$ In order to preserve conservatism, the maximum and minimum particle size need not be varied during design basis testing, even though the PSD and PSDD have been shown to change as a result of WTP processing. The maximum particle size is important for suspending particles in Newtonian fluids. The maximum particle size, breadth of the PSD and the fraction of fine particles are important for suspension of particles in non-Newtonian fluids.

For limits of performance testing, the maximum particle size should be increased at selected particle densities to determine how large of a particle the PJMs can mobilize for removal from the vessel. This includes increasing the size of the $\mathrm{PuO}_{2}$ equivalent particles to determine the maximum size non-coprecipitated $\mathrm{PuO}_{2}$ particle that can be mobilized.

Due to practical considerations based on the physical limitations of materials, WTP should not attempt to increase the density of the particles beyond the range described above during the limits of performance testing. Particle settling and suspension are affected by both particle size and particle buoyancy $\left(\rho_{S} / \rho_{L}-1\right)$. Changing particle size can produce similar behavior to changing particle density. Design equations being developed and tested during LSIT give guidance on the equivalent size-for-density relationships when tests representing higher particle densities are necessary. These relationships are expected to vary depending on test objective. The appropriate relationship between particle size and buoyancy will be chosen during simulant development in support of each test plan. Thus, the limits of performance can be evaluated by varying the particle size at selected particle densities. However, it is important to maintain a significant fraction of particles at sizes and densities reasonable for actual waste in order to maintain simulant representativeness.

\subsubsection{Liquid Density and Liquid Viscosity}

Hanford waste particles are transported by the supernatant and interstitial liquid as they move from the tank farm into and through the WTP tanks. This liquid is typically a multi-component salt solution with a $\mathrm{pH}$ of 12 to greater than 14 . Particle-free salt solutions typically exhibit Newtonian fluid behavior, a linear relationship between shear stress, $\tau$, and shear rate, $\dot{\gamma}$, as $\mu_{L}=$ $\tau / \dot{\gamma}$. The two liquid-phase properties generally associated with particle settling and suspension are liquid density $\left(\rho_{L}\right)$ and liquid viscosity $\left(\mu_{L}\right)$, which often appear together as a ratio, the kinematic viscosity $\left(v_{L} \equiv \mu_{L} / \rho_{L}\right)$. The liquid-phase densities and viscosities of salt wastes have a 
weakly correlated direct relationship (i.e., highest viscosities are typically encountered in the highest density liquids). ${ }^{8}$

The majority of the LSIT program will not be performed at elevated temperatures even though two process vessels in the WTP are mixed at elevated temperatures. ${ }^{2}$ To simulate processes requiring elevated temperatures, the kinematic viscosity could be adjusted to compensate. The kinematic viscosity could also be impacted by salt dissolution at elevated temperatures.

A system containing a Newtonian liquid plus a dispersion of non-interacting, modest to largesized solid particles often behaves as a Newtonian liquid under shear. The slurry viscosity of such a solid-liquid system, however, is typically greater than the Newtonian viscosity of the liquid phase. The Newtonian slurry viscosity is typically a function of the particle volume fraction and PSD.

The following are the recommendations for ranges of liquid density and viscosity for Newtonian fluids. The LSIT should test liquids with a density of $1.00-1.46 \mathrm{~g} / \mathrm{mL}$. The slurry density of LAW feed to WTP is limited to no more than $1.46 \mathrm{~g} / \mathrm{mL},{ }^{11}$ thus also limiting the liquid phase density in the LAW feed to no more than $1.46 \mathrm{~g} / \mathrm{mL}$. To reduce the liquid density below $1.0 \mathrm{~g} / \mathrm{mL}$ would require heating the test vessel or adding a lower density solvent to the simulant. The LSIT should test liquids with viscosity of $1-15 \mathrm{cP}$ for Newtonian vessels ${ }^{17}$ and $1-30 \mathrm{cP}$ for Newtonian fluids in non-Newtonian vessels. It may be challenging to achieve maximum density and viscosity simultaneously for the Newtonian vessels. The expected range of the kinematic viscosity is $1.0 \times 10^{-6}-1.1 \times 10^{-5} \mathrm{~m}^{2} / \mathrm{s}$ for Newtonian vessels. These recommendations are consistent with those made for related TOC simulants, although higher maximum densities and viscosities are applicable to the tank farm. ${ }^{14}$

Because of the small change in liquid density and the difficulty in obtaining a simulant with density less than $1 \mathrm{~g} / \mathrm{mL}$, the liquid density range should not be expanded in the Limits of Performance testing. Because the liquid viscosity has less impact on PJM mixing than particle size, particle density, yield stress, and shear strength, the liquid viscosity range should not be expanded in the Limits of Performance testing. For Newtonian fluids, the liquid portion of the simulant used in the Limits of Performance testing should use the low end of the ranges of both density $(1.0 \mathrm{~g} / \mathrm{mL})$ and viscosity $(1.0 \mathrm{cP})$. A confirmatory test should be conducted using a liquid with density of $1.46 \mathrm{~g} / \mathrm{mL}$ and a viscosity of $15 \mathrm{cP}$. Non-Newtonian rheology is considered in Section 2.1.4.

\subsubsection{Archimedes Number}

The Archimedes number is a useful dimensionless group that combines several key properties into one parameter. The Archimedes number, Ar, is defined as

$$
\operatorname{Ar}=d_{P}^{3} g\left(\rho_{S} / \rho_{L}-1\right) / v_{L}^{2}
$$

where $g$ is the gravitational acceleration constant. The Archimedes number is a measure of the ratio of buoyancy forces to viscous forces. Viscous forces dominate at small Ar, while buoyancy forces dominate at large Ar. The Reynolds number for a settling particle, $\mathrm{Re}_{\mathrm{P}}$, is a function of the particle size, kinematic viscosity, and terminal settling velocity, $V_{S}$, and is defined as

$$
\operatorname{Re}_{\mathrm{P}}=V_{S} d_{P} / v_{L}
$$


An analogous Reynolds number can be defined using the particle-to-liquid slip velocity, but this has no impact on the properties that matter to mixing. The settling $\mathrm{Re}_{\mathrm{P}}$ is a two-constant function of the Archimedes number in each of the three distinct settling regimes (Stokes, Intermediate, and Newton) using the approximations for the drag coefficient given in Ref. 5 (page 2.2).

$$
\operatorname{Re}_{\mathrm{P}}=C * \mathrm{Ar}^{n}
$$

$\begin{array}{llll}\text { Stokes } & C=1 / 18 & n=1 & \operatorname{Re}_{\mathrm{P}} \text { variably defined as }<0.3 \text { (or } 0.1 \text { or } 1 \text { ) } \\ \text { Intermediate } & C=1 / 6.54 & n=5 / 7 & 0.3<\operatorname{Re}_{\mathrm{P}}<1,000 \\ \text { Newton } & C=1.74 & n=1 / 2 & 1,000<\operatorname{Re}_{\mathrm{P}}<200,000\end{array}$

The Froude number is a third dimensionless group used in some studies that is related to the Reynolds and Archimedes numbers. The square root of the Archimedes number equals the Reynolds number divided by the Froude number. Knowing any two of these groups is equivalent to knowing all three through this relationship. The Archimedes number was selected for use in this document because it only contains chemical and physical properties. Both the Reynolds and Froude numbers contain a characteristic velocity. Consequently, neither group was included in the list in Section 1.4 which excludes parameters directly tied to momentum. Using the Reynolds-Froude number pair in mixing correlations can give rise to a complex functionality for the velocity design variable.

The Archimedes number has a distribution of values for a waste slurry (analogous to a PSD or PSDD). It can be determined from a PSDD calculation with knowledge of the liquid viscosity and liquid density.

Three properties are evident in the Archimedes number. The most significant property is the particle size, which is present to the third power. Waste slurries span many orders of magnitude in Archimedes number through the particle size alone. The second significant parameter is the buoyancy, $\rho_{S} / \rho_{L}-1$, also called the dimensionless solid-liquid density difference. The buoyancy can vary from about 0.5 to greater than 10 for primary particles and can approach neutral buoyancy $\left(\rho_{S} / \rho_{L} \approx 1\right)$ for waste agglomerates leading to order of magnitude ranges in Archimedes number. The third property is the kinematic viscosity, which varies by about a factor of 10 for the liquid concentrations and temperature ranges expected in actual waste.

Design equations for mixing, settling and transport typically have terms in particle size, dimensionless solid-liquid density difference, and kinematic viscosity which can be grouped to form an Archimedes number. The Archimedes number is a significant correlating term and it spans a wide range of values when compared to the individual properties that it contains.

Previous analysis of Hanford waste showed Ar to vary from $1 \times 10^{-7}$ to $1 \times 10^{5}{ }^{14}$ That analysis assumed $1441 \mu \mathrm{m}, 7.14 \mathrm{~g} / \mathrm{mL}$ particles to be present. A $700 \mu \mathrm{m} \mathrm{Na} \mathrm{UO}_{2}\left(\mathrm{CO}_{3}\right)_{3}$ particle (density of $3.0 \mathrm{~g} / \mathrm{mL})^{18}$ would have an Ar of $6.7 \times 10^{3}$. This particle size is based on the WTP design limit, this density is based on a large particle previously observed in a Hanford sample, and the liquid kinematic viscosity is taken at the minimum value. The range of Ar for the LSIT Performance Testing and Scaling should be $1 \times 10^{-7}$ to $6.7 \times 10^{3}$. If a $100 \mu \mathrm{m}$ diameter $\mathrm{PuO}_{2}$ particle existed in WTP, its Ar would be $1.02 \times 10^{2}$, which is within the Ar range recommended for testing.

For Limits of Performance testing, the upper limit can be accomplished by increasing the particle size of the large particles and the dense particles in order to determine the limits for mixing and transport in WTP. The Archimedes number will be increased through increases in particle size 
(see Section 3.0) to cover both changes in size and density. It is recommended that relatively dense particles be used to simulate other dense particles and that relatively light particles simulate other light particles so that uncertainty of using size to account for density differences will be minimized.

\subsubsection{Non-Newtonian Suspensions of Solid Particles}

At sufficiently low solids concentrations, slurries of cohesive solids can act like Newtonian liquids. Cohesive solids are those small enough to possess behaviors affected by interparticle forces. At moderate and high solids concentrations, slurries of cohesive solids can exhibit nonNewtonian behavior (i.e., shear-thinning, shear-thickening, creep/recovery and other mild versions of viscoelastic behavior). Slurries of larger particles tend to be heterogeneous suspensions that are not well modeled as pseudo-homogeneous media. Proper classification of the slurry is important to understanding the expected rheological behavior.

The two-parameter Bingham plastic equation is generally sufficient for steady, non-Newtonian irrotational shear flow applications and has been the primary method employed to characterize HLW slurry test results to date. The two parameters in the model are the Bingham yield stress $\left(\tau_{Y S}\right)$ and consistency $(\eta)$, which are fit respectively to the intercept and slope of the flow curve data (a graph of shear stress as a function of shear rate).

$$
\tau=\tau_{Y S}+\eta \dot{\gamma}
$$

The basis of design for yield stress and consistency in WTP non-Newtonian vessels is $6 \mathrm{~Pa}$ and 1 $\mathrm{cP}$ to $30 \mathrm{~Pa}$ and $30 \mathrm{cP} .^{10}$ This range is more appropriate for LSIT testing than the actual range of yield stress and consistency measured on waste tank core samples. The as-received HLW slurry is currently limited to a yield stress of less than $1 \mathrm{~Pa}^{11}$ and this serves as the upper limit for yield stress in the Newtonian vessels.

While the Bingham plastic model can be used to describe some steady non-Newtonian flow systems, pulse jet mixing of slurries in the WTP is not a steady shear application. The Bingham model has no parameters for rotational or time-dependent phenomena, and thus has some limitations. ${ }^{19}$ Consequently, matching the two Bingham parameters in a simulant to those for a waste sample does not guarantee identical mixing behavior in a PJM vessel. This possibility has been recognized in earlier work (e.g. Ref. 20, Section 3.3.1) and is mentioned here because it introduces uncertainty in the simulant testing. However, the Bingham yield stress is a measurable property for which a large data set exists on Hanford tank wastes and has been used in WTP design.

Performance Testing and Scaling will need to be performed at the design limit values for yield stress and consistency, as well as at intermediate values. Intermediate values may potentially be more challenging to some test objectives than the design limit values. The Limits of Performance testing needs to evaluate lower values of yield stress (between $6 \mathrm{~Pa}$ and $1 \mathrm{~Pa}$ ) and higher values of yield stress and consistency (greater than $30 \mathrm{~Pa}$ and $30 \mathrm{cP}$ ). For non-Newtonian tests in the Newtonian vessels, Limits of Performance testing needs to evaluate a yield stress of greater than $1 \mathrm{~Pa}$. 


\subsubsection{Properties for Beds of Settled Particles}

Shear strength (measured by vane rheometry) is the point at which a solid ceases to deform like a solid and begins to flow like a liquid. The critical shear stress for erosion is the applied stress above which a particulate would be removed from a surface or body. These are both related properties for beds of settled particles. These waste properties should be simulated for tests that represent conditions in which regions of settled solids can accumulate. These two properties apply regardless of whether the vessels are classified as Newtonian or non-Newtonian based on well-mixed bulk slurry properties. The critical shear stress for erosion is conceptually similar to the shear strength of a bed of settled solid. However, the relationship between these two properties will differ for different systems.

The shear strength of a settled bed that is held quiescent and allowed to become more consolidated tends to increase as a function of time. Vane measurements of the settled layers are quantitative lab-scale measures of the shear strength and are dependent on material history. The shear strength is dependent on the particle shape, interparticle forces and microstructure. ${ }^{21}$ Shear strength is influenced by compaction time, weight under which compaction occurs, and degree of saturation of the pore space.

Critical shear stress is typically measured in an engineering test bed rather than using a laboratory instrument. Historically, Hanford and the Savannah River Site (SRS) have measured shear strength rather than critical shear stress for actual waste samples.

Shear strength and critical shear stress for erosion are most applicable to the LSIT program where resuspension of zones of settled particles from the vessel floor is important, including the PJM restart and heel management test objectives.

Several reviews of Hanford waste properties and WTP testing included information on the expected shear strength to be encountered in WTP PJM-mixed vessels. A typical shear strength of $30 \mathrm{~Pa}$ is expected as the result of not mixing WTP slurries for 1 day. ${ }^{6}$ As a reasonable minimum upper bound based on simulant testing, a settled layer shear strength of up to $200 \mathrm{~Pa}$ can be expected after a day of not mixing, though there is uncertainty in this estimate. ${ }^{2,6}$ WTP design includes standby air compressors that will allow for at least an hour of mixing daily.

The design basis shear strength is up to $200 \mathrm{~Pa}^{6}{ }^{6}$ During the Limits of Performance testing, the shear strength should be increased from $200 \mathrm{~Pa}$ to at least $1400 \mathrm{~Pa}$ (based on Ref. 22) to determine the maximum shear strength slurry that the PJMs can remobilize sufficiently to release trapped gases from settled solids. These higher shear strengths could be attained if the plant experiences long outages.

\subsubsection{Undissolved Solids Concentration}

The UDS concentration, either as a volume or weight fraction, is not constant during WTP processing. Several WTP processes, including caustic and oxidative leaching, washing, and filtration, will change the UDS concentration of the waste. UDS concentration influences the flow behavior of the jet produced by the PJMs as well as the slurry viscosity (Newtonian tanks) or Bingham yield stress (non-Newtonian tanks). UDS concentration is also a variable that impacts the settling regime, with lower solids concentration favoring free settling over hindered 
settling. For beds of settled solids, the solid particle concentration influences the settled solids bed depth, shear strength, and critical shear stress for erosion.

UDS concentration of a simulant should approximate that of actual waste at each point in the WTP process. Solids volume fraction controls the ratio of liquid volume to solid volume in the system when particles are well suspended, as well as influencing the depth of settled solids that can form when mixing is lost for an extended period. Attaining the proper ratio of the two phases contributes to the representativeness of the simulant. If the ratio is significantly different from that of actual waste, then it could be argued that the mixing problem being studied by LSIT is not the same as what will occur during actual WTP operations.

For Newtonian simulants, the UDS concentration should range from nearly 0 to $10 \mathrm{wt} \%$. UDS concentration for CFD V\&V testing will range up to $12 \mathrm{wt} \%$ in order to provide sufficient margin. ${ }^{17}$ Tests should be performed over this range of UDS concentrations, including but not limited to either extreme because either may be the more challenging. Limits of performance testing should increase the UDS concentration outside of this range.

For non-Newtonian simulants, the solids concentration will be varied to impact the yield stress and consistency. The maximum concentration of UDS will be that needed to achieve a yield stress of $30 \mathrm{~Pa}$, a consistency of $30 \mathrm{cP}$, and a shear strength of $200 \mathrm{~Pa}$. Ideally, the UDS concentration for the simulant should be within the range required to achieve similar rheology in actual waste. During limits of performance testing, the solids concentration should be changed as needed to increase or decrease the yield stress and shear strength.

\subsection{Particle Shape}

Particle shape potentially influences two main physical processes within PJM-mixed vessels during LSIT: 1) the settling of solid particles, and thus the ability to keep the large and dense particles suspended; and 2) the remobilization of settled particles or beds of particles. The particle shape influences these two processes differently, and thus they are addressed separately. Particle shape and surface roughness also impact particle adhesion to surfaces, as discussed in Appendix A. This section reviews what is known about particle shape in Hanford wastes, the influence of particle shape on settling, and the influence of particle shape on suspension and bed erosion.

Particle shape influences settling rate, with spherical particles providing the maximum settling rate. Particle shape may influence the ability to suspend particles off the bottom of a tank, where some evidence exists that nonspherical particles require an increased velocity for off-bottom suspension. Particle shape is one of several factors that impacts the remobilization of solids through its influence on the shear strength of beds.

\subsubsection{Particle shape in Hanford waste}

A tabulated summary of particle shapes in Hanford tank farm waste is included in the review of property data and gaps (Ref. 5, Section 3.2.4.12, Table 3.13). This summary presents the data in terms of Corey's shape factor $\left(S_{F}=c / \sqrt{a b}\right)$, where $a, b$ and $c$ are the longest, intermediate and shortest mutually perpendicular axes of the particle, respectively. Shape factors are tabulated for a limited set of waste constituents focusing on the most nonspherical particles, and only for 
primary particles. Additionally, no range, variability, or uncertainty is presented and no information exists from which to construct a technically defensible basis for a distribution of particle shapes in Hanford wastes. Of note, shape factors were included for boehmite $\left(S_{F}=0.26\right)$ and $\mathrm{PuO}_{2}\left(S_{F}=0.5\right){ }^{5}$ Several other shape factors were presented in Ref. 5, but were for soluble salts. The reported shape factors for the primary particles identified in Hanford tank samples ranged from 0.26 to $1 .^{5}$

Washing, caustic leaching, and oxidative leaching all can change the particles in the waste and may change the particle shape. A basis for this potential shape change has not been developed.

\subsubsection{Shape impacts on particle settling}

Fluid mechanics relationships developed for the drag coefficient often consider the influence of particle shape. ${ }^{23,24,25}$ The drag coefficient and terminal velocity of a nonspherical particle have been related empirically to its equal volume sphere diameter $\left(d_{S}\right)$ and its sphericity. ${ }^{26,27,28}$ Most of these analyses are for the free fall of individual particles. Much less information is available for the influence of particle shape on settling in the hindered settling regime.

A concern when comparing systems of different particle shapes is the use of a characteristic particle size. Advantages of using $d_{S}$ are that it is used in the sphericity definition and the resulting correlations, and that at constant $d_{S}$ spherical particles are the fastest settling shape. Corey's shape factor used in Ref. 5 and the sphericity do share some characteristics: perfect spheres would have a shape factor of 1 and deviations from spheres would have a shape factor between 1 and 0 .

The influence of particle shape on the drag coefficient is dependent on the settling regime. Based on expected WTP processing, the majority of individual particles are in the Stokes settling regime. Towards the higher end of particle size and density expected in WTP, the particles will be in the Intermediate settling regime. It is not expected that the Newton settling regime would be encountered. A hypothesized bounding case of a large dense particle $\left(d_{P}=1 \mathrm{~mm}, \rho_{S}=11.4\right.$ $\mathrm{g} / \mathrm{mL})$ settling in water would still be in the Intermediate settling regime $\left(\operatorname{Re}_{\mathrm{P}} \approx 500\right)$.

Orientation during free fall is a function of $\mathrm{Re}_{\mathrm{p} .}{ }^{25}$ In the low $\mathrm{Re}_{\mathrm{p}}$ Stokes regime, all settling orientations are stable. As $\mathrm{Re}_{\mathrm{p}}$ is increased, settling is stable in the orientation of maximum drag. At higher $\mathrm{Re}_{\mathrm{p}}$, the particle orientation during settling becomes unpredictable, with wobbling and rotation possible. At high $\mathrm{Re}_{\mathrm{p}}$, particles rotate about the axis of least inertia.

With some minor exceptions, spheres are the fastest settling particles when compared to nonspherical particles of the same volume. For spheroids and ellipsoids with shapes ranging from disks to needles, the minimum drag shape for a given particle volume when averaging over all orientations is a sphere. ${ }^{29}$ When considering specific orientations of such shapes with respect to the flow direction, some objects have a very slight $(<5 \%)$ drag reduction from that of a sphere of the same volume. ${ }^{29}$ Because this occurs for orientations only stable in the Stokes settling regime, this is not applicable to the most bounding or challenging situations for LSIT. The influence of this slight reduction in the free settling velocity from that of a sphere is well within the other uncertainties involved with PSDD, and thus free falling spheres can be considered to provide the practical maximum settling velocity during testing.

For settling, particle surface roughness (small length scale roughness) does not strongly influence settling until $\mathrm{Re}_{\mathrm{p}}$ is in the high Newton range that will not be encountered in WTP tanks. ${ }^{29}$ 


\subsubsection{Shape impacts on particle suspension and bed erosion}

Particle shape can influence the behavior of particles during suspension. Testing on suspension by gas streams revealed that spherical particles start their motion by rolling and large nonspherical particles start their motion by sliding. ${ }^{30}$ This change in mechanism in turn changes the amount of particle-surface friction, thus leading to higher velocities required to initiate motion of large non-spherical particles than for analogous spherical particles. ${ }^{30}$ This incipient motion is usually the precursor to particle pickup and entrainment in the liquid. Pickup velocity studies of spherical and non-spherical particles proposed adjustments to the Archimedes number to compensate for the higher velocities needed for the suspension of non-spherical particles. ${ }^{31}$

For specific systems, particle shape influences removal of particles from a stationary bed by a liquid. $^{32}$ For some systems, the effect of particle shape on particle suspension can be less pronounced for higher solids (i.e. $10 \mathrm{wt} \% \mathrm{UDS}$ ) loadings than for low solids loadings (isolated particles). ${ }^{32}$

Particle shape is one of the factors that influence the shear strength of a settled layer. ${ }^{21}$ This influence can be due to factors such as surface forces, friction, and solids packing. While spheres contact each other at a single point, non-spherical particles can contact each other at one or more points, lines, or planes. For small non-spherical particles, surface forces can act over larger particle contact areas than for spheres. ${ }^{33}$ This can lead to large deviations (but similar average values) for critical suspension velocities of non-spherical particles relative to those for spheres. ${ }^{33}$ Non-spherical material can potentially have higher pickup velocity than spherical material due to particle-particle interlocking that occurs for non-spherical particles. ${ }^{33}$

\subsubsection{Recommendations for particle shape}

In testing settling of large dense particles, spherically shaped particles would provide the maximum settling rate and thus would be conservative. In testing of the remobilization of beds of solids, non-spherical particle shapes may contribute to an increased velocity needed for offbottom suspension.

As discussed in Section 2.2.1, Ref. 5 provides only limited data on the shapes of particles observed in Hanford waste samples. The shape factors reported are for the most non-spherical particles observed. The shape factors are for the primary particles, not the agglomerates. The reported shape factors ranged from $0.26-1.0$, with the lower end of the range corresponding to small boehmite primary particles that would usually be present as agglomerates. No shape factor distribution is reported.

For Newtonian and non-Newtonian simulants, LSIT should use a mixture of particle shapes, including spherical and non-spherical particles. However, because of the absence of information on the particle shape distribution in Hanford waste, the baseline simulant should not be matched to any specific range of particle shape distributions. Previous M3 and LOAM testing used simulants that contained dense nonspherical components, including irregularly shaped tungsten carbide alloy and rod shaped bismuth oxide. ${ }^{34,35}$ As spheres give the fastest settling rate, spheres should be considered for use for at least a portion of the particles at the high end of the Ar distribution. 
If desired, in the limits of performance testing, a spike of extremely flat or elongated shapes could be introduced into a baseline simulant mixture in incrementally larger proportions to investigate whether there is a discernible effect on the ability to suspend or transfer the material.

\subsection{Time Dependent (Thixotropic/Rheopectic) Rheological Phenomena}

Flow curve data from the M-12 program were examined, some of which showed hysteresis between the up and down portions of the curves. ${ }^{22,36,37,38,39}$ This hysteresis has been cited as potential evidence for time-dependent rheological behavior of Hanford wastes. ${ }^{37,38,39}$ The IP suggests that the LSIT program could consider the progressive variation in the degree of thixotropic and rheopectic behavior as potential characteristics to explore during Limits of Performance testing. ${ }^{3}$ Time-dependent rheological properties are not the only possible explanation for the small amounts of hysteresis noted on certain flow curves in the discussion that follows. This is particularly true when the sample matrix is heterogeneous (liquid-solid or gasliquid-solid) and the rheometer uses the concentric cylinder geometry with rotating inner cylinder. As acknowledged by the authors of the M-12 reports, other explanations for the observed hysteresis include solids settling out of the measurement gap, evaporation of water during measurements, and sample degassing during measurements.

Hysteresis in the initial Group 7 characterization sample was described as significant, but the flow curve in Figure 3.5 of that report showed that the area under the down curve was within $20 \%$ of the area under the up curve and that the two converged at roughly $4 \mathrm{~Pa}$ as the shear rate fell below $25 \mathrm{~s}^{-1} .{ }^{37}$ This is not an unusual amount of flow curve hysteresis for a slurry sample, particularly for systems containing a significant fraction of large particles. A subsequent flow curve of the Group 7 sample at $60^{\circ} \mathrm{C}$ instead of $25^{\circ} \mathrm{C}$ showed almost no hysteresis. Down flow curves at three temperatures were almost identical suggesting that there may have been some impact of the initial up flow curve on the nature of the sample. A constant rate of strain measurement is preferred over a flow curve ramp analysis for determining time-dependent rheological behavior.

Data for Group 8 were relatively free of hysteresis, as well as being nearly Newtonian. The up flow curves for Group 8 measurements passed into the region of Taylor vortices. Because this region was entered, the integrity of the down flow curves is potentially compromised for slurry sample matrices. ${ }^{38}$ Flow curves for the Group 1 and Group 2 initial characterization samples showed essentially no hysteresis. ${ }^{36}$ Measurements on Group 5 REDOX sludge showed very mild negative hysteresis, which is analogous to rheopectic behavior. However, the changes in areas beneath the up and down flow curves were only a few percent. ${ }^{40}$

As time-dependent rheological properties are not the only possible explanation for the hysteresis and the magnitude of the potential time-dependent rheology impacts does not appear to be significant in comparison to the WTP non-Newtonian operating range, it is not recommended that simulants of the Hanford wastes be formulated to exhibit time-dependent rheological behavior.

\subsection{Waste and Simulant Chemistry}

The effects of the chemical composition of Hanford waste slurries need to be considered in the test program. Aqueous properties change during pretreatment. Caustic and oxidative leaching, 
coupled with washing and crossflow ultrafiltration, affect the $\mathrm{pH}$ and overall ionic strength of the waste stream. While these changes in aqueous phase properties often do not produce large changes in liquid viscosity or density, they can have more significant impacts on slurry properties through their interaction with the surface characteristics of the particles.

Waste chemistry is highly significant in the testing of unit operations such as washing or leaching. Some aspects of waste chemistry also affect waste properties important to vessel mixing. These include ionic strength, $\mathrm{pH}$, zeta potential, isoelectric point, cohesiveness, and adhesiveness. Appendix A describes some of the chemical properties important to Hanford waste and to simulant design and discusses their relationship to other properties such as yield stress and shear strength.

Slurry cohesiveness will depend on particle size distribution, solid mass fraction, solid phase composition, and liquid phase composition. Underlying mechanisms for cohesiveness are discussed in Appendix A. Potential methods for representing cohesiveness in a waste simulant involve matching some of the following aspects of the waste: chemical compounds, particle sizes, surface charges, ionic strength and $\mathrm{pH}$. Ideally such a simulant would also match yield stress, consistency, and potentially shear strength when decanted to a comparable UDS concentration. By preparing a non-Newtonian slurry with cohesive particles, there is a lower risk of missing an effect that is not directly manifested in rheology.

Adhesive slurries have been observed at SRS, such as those that formed coatings on equipment surfaces at the Defense Waste Processing Facility (DWPF). The underlying phenomena for adhesion are similar to those for cohesion. Similarities between some wastes at Hanford and SRS suggest that adhesive slurries could be encountered at some point during WTP processing. Appendix A.4 gives additional background information.

\subsection{Scaling of Simulants}

The use of similitude and dimensional analysis is an approach that can be employed in developing a technical basis for scaling complex systems. When using full similitude, testing at reduced scale is designed to produce the same motion of liquids and solids relative to characteristic length and time scales for both the full-scale and reduced scale systems.

The three types of similitude are geometric similitude, kinematic similitude, and dynamic similitude. Geometric similitude means that the shape of all pertinent boundaries is the same at both scales. Kinematic similitude means that the ratio of times for similar events is the same at both scales. Dynamic similitude means that the ratio of like forces or fluxes is the same at both scales. Full similitude is obtained by having all three types simultaneously.

To obtain full similitude between reduced scale and full scale requires scaling simulant properties such as viscosity, particle size, and particle/liquid density difference to system size. Scaling of these parameters can be problematic at reduced scale and could change the controlling physical mechanisms of the process. For full similitude, the liquid viscosity must be smaller at reduced scale than full scale, and in many instances would be much less than $1 \mathrm{cP}$. In addition to viscosity, the particle size must be reduced. Reducing the particle size increases the surface to volume ratio, increasing the relative importance of surface forces. Changing the particle size may also change the flow regime in which the particles move (e.g., settling). Controlling particle size during the precipitation of chemical simulants is problematic. 
Scaling the liquid or solid properties is not generally practiced in commercial mixing studies. In addition, numerous studies by PNNL and SRNL to investigate mixing in the Hanford and SRS Tank Farms and radioactive waste treatment facilities were performed without scaling the simulant properties. Changing the liquid viscosity, particle size, or particle density difference with system size is not recommended for the large scale integrated testing. For a more detailed discussion on similitude and scaling of simulants, see Reference 41.

\subsection{Recommendations for Simulant Properties to Meet Test Objectives}

This section examines the test objectives identified in Section 1.3 and assesses the simulant properties that are important in testing different objectives. The test objectives are bottom motion/accumulation, transfer and pump out of solid particles, prototypic integrated operations, integrated sparger operation, PJM controllability, vessel level/density instrument accuracy, sampling capability, heel management, PJM restart, design and safety margin, CFD V\&V and comparison, performance testing and scaling, and high temperature operation.

\subsection{Performance Testing and Scaling}

The LSIT testing will evaluate bottom motion and the accumulation of solids by measuring the effective clearing radius (ECR) of the PJMs as a function of test parameters and feed simulant properties. For Newtonian slurries, the Archimedes number distribution and the particle concentration are the most important properties. The particle size distribution, solid-liquid density difference, settled shear strength, and liquid kinematic viscosity are included in the Archimedes number distribution. The liquid kinematic viscosity and PSD can have additional impacts beyond the Archimedes number. For non-Newtonian slurries, the slurry yield stress, slurry consistency, settled shear strength, solid-liquid density difference, and particle size are the most important properties. Properties such as particle shape, breadth of the particle size distribution, number of fine particles, ionic strength, $\mathrm{pH}$, particle surface charges, and particle concentration will affect the slurry yield stress, slurry consistency, and shear strength, and these properties can affect the bottom motion and accumulation of particulate solids. These properties should be considered when developing simulants.

The objectives of the transfer and pump out tests are: ${ }^{2}$

- Show that the transfer system will not plug under normal vessel operating conditions.

- Demonstrate that the transfer performance meets the design requirements across the range of slurry properties in Newtonian and non-Newtonian conditions.

- Demonstrate that the pump suction nozzle in the vessel does not plug with solids.

For Newtonian slurries, the most important properties are the Archimedes number distribution and the particle concentration. For non-Newtonian slurries, the important properties are the slurry yield stress, the slurry consistency, the solid-liquid density difference, and the particle size. Since the vessel contents will be mixed prior to starting a transfer or pump out, the shear strength is not an important parameter for this test function. Chemical effects that are not reflected in slurry rheology could impact the ability of the solids to plug the pump suction nozzle or transfer system. 
Prototypic integrated operation will demonstrate pulse jet pump pair operation at full-scale. The control of pressure and vacuum being applied to the PJM will be investigated in a prototypical environment, i.e. full scale tank with functioning level indication, air sparging, etc. in a mock-up test unit functionally identical to the actual PTF tanks. Confirmation of design correlations (scaling relationships) for total bottom motion, etc. will need to be verified experimentally. Ideally, no net accumulation of solids should occur from batch to batch.

The most important properties for the prototypic integrated operations testing with Newtonian fluids are the Archimedes number distribution and the particle concentration. For non-Newtonian fluids, the most important properties are the slurry yield stress, the slurry consistency, the solidliquid density difference, and the particle size.

Spargers are employed in non-Newtonian vessels to mix the vessel contents in the region outside of the mixing cavern created by the PJMs. The objectives for integrated sparger operation testing during LSIT are: ${ }^{2}$

- Demonstrate PJM controls with integrated sparger operation.

- Demonstrate that sparger operation does not interfere with other required functions, such as pump out, monitoring, vessel level/density instrument operation and accuracy, and PJM mixing.

- Gather data across the range of anticipated fluid properties to address unverified sparger design assumptions for sparger sizing and placement.

The spargers are not placed in Newtonian tanks, but UFP-2 will experience Newtonian fluid behavior when it contains low concentrations of solid particles. The important properties for Newtonian slurries are the Archimedes number distribution and the particle concentration. For non-Newtonian slurries, the important properties are the slurry yield stress, the slurry consistency, the solid-liquid density difference, and the particle size. These are the quantities that should vary across the range of anticipated fluid properties for both tests. Since the vessel bottom will be mixed with PJMs when the spargers are operating, the shear strength is not an important parameter for this test objective. If the LSIT wants to examine foaming or gas retention during the sparger tests, testing should select a simulant with properties that reflect the foaming and gas retention observed with actual waste.

PJM controllability involves testing to confirm that an actual process control system for the PJM air-vacuum pulses will function correctly at large scale in representative systems prior to cold runs. The following are the test objectives for PJM controllability: ${ }^{2}$

- Perform level/density PJM control testing over the full range of processing parameters to determine if the current PJM baseline controls will achieve the mixing requirements should the pressure feedback approach be unsuccessful or an alternative design be considered warranted.

- Test the logic for normal PJM control during all operational modes.

- Test the logic for off-normal PJM control during all operational modes.

- Test the PJM controls in situations that involve operation of the PJMs at elevated temperatures.

The important properties for Newtonian slurries are the Archimedes number distribution and the particle concentration. For non-Newtonian slurries, the important properties are the slurry yield stress, the slurry consistency, the solid-liquid density difference, and the particle size. 
The objective for the vessel level/density instrument accuracy tests is to evaluate the accuracy of the submerged bubbler tubes in measuring the vessel fluid level with a slurry that has a density changing with time and elevation. For Newtonian slurries, the simulant should be designed to have a high solids concentration and either a broad particle size or Ar distribution. For nonNewtonian slurries, the simulant should be designed to have a broad particle size distribution and a large solid-liquid density difference. If WTP is interested in evaluating the impact of air entrainment on the vessel level/density accuracy, it needs to select a simulant that entrains air similarly to an actual waste.

Sampling capability tests will be performed using a prototypic sampler. Testing is intended to characterize sample variability relative to actual vessel content. Additional objectives for the 14$\mathrm{ft}$ platform include a demonstration of the ability to obtain representative samples of the solids and liquids in PJM vessels, including demonstrating that representative samples can be obtained if the assumed WTP design particle size or density is exceeded. This goal is tied to safety-related issues in the WTP.

The test objectives related to sampling capability during LSIT are: ${ }^{2}$

- Demonstrate sampling capability using a prototypic sampler configuration to gain an understanding of the sample variability relative to the actual vessel content.

- Determine the capability of the system to obtain samples for analysis that can be compared to the vessel inventory at the pump suction location in the vessel.

- Determine sample variability at different PJM cycle points.

- Determine sample variability at different vessel levels.

- Determine the maximum PSDD that sampling can detect.

- Demonstrate that representative samples can be obtained if the WTP design basis particle size or density is exceeded.

A statistically defensible number of different compounds should be used in the simulant. Due to the relatively small inner diameter of the sampler needle $(3.4 \mathrm{~mm}),{ }^{42}$ particles that are sufficiently large may encounter physical interference that would create a bias toward their exclusion from samples. Thus for this test objective, it may become important to control particle size outside of its effect on the Archimedes number. The important properties for Newtonian fluids are the Archimedes number distribution (or individually, particle size, particle/liquid density difference, and kinematic viscosity) and the particle concentration. The important properties for the nonNewtonian slurries are the slurry yield stress, the slurry consistency, the solid-liquid density difference, and the particle size.

Heel management system testing will be performed on the 4, 8, and 14-foot diameter test platforms. Residual heels containing elevated concentrations of solids may remain in the vessel following batch transfers. The heel removal system is designed to remove these solids. Heel removal equipment is currently planned for tanks HLP-22, $-27 \mathrm{~A} / \mathrm{B}$, and -28; UFP-01A/B, $02 \mathrm{~A} / \mathrm{B}$; and FEP-17A/B. Heel management will involve the use of a wash ring through which chemicals can be added to the vessel, the lowering of pump suction position, and the use of pumps that operate with less head. ${ }^{2}$ The important properties for Newtonian slurries are the Archimedes number distribution and particle concentration. Shear strength is also important if immobilized regimes are postulated. The important properties for the non-Newtonian slurries are the slurry yield stress, the slurry consistency, the shear strength, the solid-liquid density difference, and the particle size. The slurry should consist of material that is challenging to 
mobilize, such as material containing irregularly shaped particles, large dense particles, and/or adhesive particles.

Testing to support PJM restart is expected to be performed using only the 14-foot diameter test platform. During off-normal conditions when PJM operation is stopped for a period of time, waste properties for pumping are expected to change. In both Newtonian and non-Newtonian tanks, solid particles can settle into beds that will develop a shear strength that the PJMs will need to overcome in order to resume waste mobilization.

The key data needs for PJM restart testing are: ${ }^{2}$

- Demonstrate that settled Newtonian waste can be remobilized

- Demonstrate that large, fast-settling solids in non-Newtonian fluids can be remobilized from a settled bed overlaid with non-Newtonian slurry particles.

The important properties for Newtonian fluids are the Archimedes number distribution, the particle concentration, and the settled solids shear strength. For non-Newtonian slurries, the important properties are the slurry yield stress, consistency and shear strength. Chemical properties of the simulant could impact the behavior of the settled bed due to factors such as cohesiveness and adhesiveness. Once the shear strength is overcome and portions of the bed are remobilized, the properties that matter for the PJM restart task will mirror those that are important for other mixing functions (e.g., bottom motion).

Testing in support of the design and safety margin for mixing to support safety functions will be performed. Two of the key safety functions of mixing in PJM tanks are:

- Avoiding solids accumulation to prevent a buildup of fissile solids

- Attaining full bottom motion to prevent a buildup of retained flammable gas

The important parameters for Newtonian slurries are the Archimedes number distribution, the particle concentration, and the shear strength. The important parameters for the non-Newtonian slurries are the slurry yield stress, the slurry consistency, the shear strength, the solid-liquid density difference, and the particle size.

Computational fluid dynamics modeling is being used to verify the design of the PJM-mixed vessels. In order to verify the WTP design, testing will be conducted to V\&V the CFD model. ${ }^{2}$ Additional testing will be conducted to collect data for comparison to CFD calculations. The important parameters for Newtonian slurries are the Archimedes number distribution, the particle concentration, the liquid viscosity, and the liquid density. While the liquid density and viscosity typically have less importance than the Archimedes number and particle concentration, they will be important in the testing to measure fluid velocities and miscible liquid blending. The planning documents for CFD V\&V testing contain particle Reynolds number ranges rather than Archimedes number distributions. ${ }^{17,43}$ While no testing is currently planned with non-Newtonian slurries, the important properties for these slurries are included in case the test objectives should change. The important properties for the non-Newtonian slurries are the slurry yield stress, the slurry consistency, solid-liquid density difference, and the particle size.

Performance testing and scaling related testing will be performed on the 4-foot, 8-foot, and 14foot diameter test platforms. Mixing performance testing is to determine that the key mixing criteria are maintained and do not deteriorate as test vessel size increases. The focus is the effect 
of vessel size on performance. Scaling testing will evaluate the scaling of the PJM jet velocity for on-bottom motion and accumulation. The focus is on determining the velocity at which the criteria are no longer met at each scale.

The properties that are important for Newtonian slurries are the Archimedes number distribution, the particle concentration, and the shear strength. The properties that are important for nonNewtonian slurries are the slurry yield stress, the slurry consistency, the shear strength, the solidliquid density difference, and the particle size.

The objective of the high temperature operation testing is to demonstrate the ability of the PJM control system to operate the PJMs without producing overblows. At high temperatures, the liquid density and viscosity will be less than at ambient temperature. In addition, the yield stress and consistency may be different. The important parameters for the Newtonian slurries are the liquid density and viscosity, and solids concentration. For the non-Newtonian slurries, the important parameters are the slurry yield stress, slurry consistency, and the slurry density.

\subsection{Limits of Performance Testing}

The Limits of Performance testing will look at four types of tests: Newtonian, non-Newtonian, heel management, and PJM restart. The test objectives involve bottom motion/accumulation, transport/pump out, and sampling capability.

The important properties for Limits of Performance testing with Newtonian fluids are particle size, particle concentration, and range of selected densities. The bottom motion/accumulation tests should use progressively larger particles and higher solids loading with particles of selected densities. Limits of Performance testing should use particles with a large particle size and water as the liquid. The same simulant particles from the Performance Testing and Scaling tests for bottom motion and accumulation should be used for the background matrix. The tests will initially add spikes of solid particles at selected densities with increasing size until the PJM cannot obtain complete bottom motion. Once the maximum particle size is determined, additional tests should be conducted with increasing particle concentration to determine the limit for complete bottom motion. Once the limits for particle size and particle concentration are determined, an additional confirmatory test with the maximum particle size and concentration should be conducted using a liquid with density of $1.46 \mathrm{~g} / \mathrm{mL}$ and a viscosity of $15 \mathrm{cP}$. Additional tests should be conducted with the maximum particle size and particle concentration to determine if complete bottom motion can be obtained with a slurry of yield stress greater than $1 \mathrm{~Pa}$.

The approach used for bottom motion/accumulation should also be employed to determine the maximum size particle and the maximum particle concentration that can be transferred from the Newtonian vessels and the maximum size particle and particle concentration that can be sampled effectively with the WTP samplers.

The important properties for Limits of Performance testing with non-Newtonian fluids are yield stress, consistency, and particle size. These rheological properties can be increased by increasing the $\mathrm{wt} \%$ UDS. The bottom motion/accumulation limits tests with non-Newtonian fluids should examine the upper and lower limits of slurry yield stress and consistency. The design basis is 6 $\mathrm{Pa}, 1 \mathrm{cP}$ to $30 \mathrm{~Pa}, 30 \mathrm{cP}$. LSIT tests should be performed with slurries of yield stress less than 6 $\mathrm{Pa}$ to determine the conditions at which the PJMs cannot mobilize large, dense solid particles, and 
with increasing yield stress above $30 \mathrm{~Pa}$ and consistency above $30 \mathrm{cP}$ to determine the conditions where complete bottom motion is not achieved.

The approach used for bottom motion/accumulation should also be employed to determine the minimum and maximum yield stress slurry that can be transferred from the non-Newtonian vessels, as well as the minimum and maximum yield stress that allows the slurry to be sampled effectively with the WTP samplers.

The important property for Limits of Performance testing of PJM restart is shear strength. The limits of performance testing for the PJM restart objective should increase the shear strength above $200 \mathrm{~Pa}$ (for Newtonian and non-Newtonian vessels) until the PJMs cannot clear sufficient area on the vessel bottom to release trapped gases. No transfer/pumpout or sampling tests are needed for this objective. Suspension will be verified visually during LSIT. Newtonian vessel testing should be performed at a viscosity of $1 \mathrm{cP}$ in water. Non-Newtonian vessel testing should be performed with a slurry with a yield stress of $30 \mathrm{~Pa}$ and consistency of $30 \mathrm{cP}$. Once the particles are suspended, the transfer and sampling behavior would be the same as that for tests supporting other test objectives.

The important properties for Limits of Performance testing for heel management are particle size, shear strength, solids concentration, and solids quantity. There are two types of testing to determine the Limits of Performance for heel management. The first type of test should use progressively larger particles and higher solids loading with particles of selected densities. The second type should increase the shear strength and quantity of a settled solid layers to determine when heel particles are no longer mobilized sufficiently to be removed from the vessel. The same approach will be used to determine the Limits of Performance for transfer/pumpout and sampling as related to heel management.

The behavior of systems containing irregularly shaped particles spanning a wide range of particle sizes may not be as unusual as the behavior seen for monodisperse systems of irregularly shaped particles in the literature. Furthermore, simulants used in the various tests are expected to contain some degree of deviation from spherical shapes. If desired, a spike of extremely flat or elongated shapes could be introduced into a baseline simulant mixture in incrementally larger proportions to investigate whether there is a discernible effect on the ability to suspend or transfer the material.

\subsection{Summary of Properties Important to LSIT Simulants}

From examining the test objectives and the discussion of the properties that matter, the most important properties for Newtonian simulants in the LSIT are the Archimedes number distribution, the particle concentration, and the shear strength. For the CFD V\&V, CFD comparison, and the high temperature tests, the liquid density and viscosity are important. The most important parameters for the non-Newtonian simulants are the slurry yield stress, the slurry consistency, the shear strength, the solid-liquid density difference, and the particle size.

Table 2 summarizes the important properties for Newtonian fluids, while Table 3 does the same for non-Newtonian fluids. Properties were ranked by potential significance as high, medium, or low for each test objective. The effects of some properties were seen as either negligible or unknown, and these were omitted from the tables. Two factors were considered in making the ranking determinations. These were the exponents (coefficients) on the property in typical scaling correlations as well as the range of property values likely to be encountered in actual 
Table 2: Properties important for LSIT with Newtonian Slurries

\begin{tabular}{|l|l|l|l|l|l|}
\hline Test Objective & Ar ${ }^{\&}$ & Concentration & $\begin{array}{l}\text { Shear } \\
\text { Strength }\end{array}$ & $\begin{array}{l}\text { Liquid } \\
\text { Density }\end{array}$ & $\begin{array}{l}\text { Liquid } \\
\text { Viscosity }\end{array}$ \\
\hline $\begin{array}{l}\text { Bottom } \\
\text { motion/accumulation }\end{array}$ & High & High & Medium & Low & Low \\
\hline Transfer/Pumpout & High & High & Low & Low & Low \\
\hline $\begin{array}{l}\text { Prototypic Integrated } \\
\text { Operations }\end{array}$ & High & High & Low & Low & Low \\
\hline Sparging & High & High & Low & Low & Low \\
\hline PJM Controllability & High & High & Low & Low & Low \\
\hline Vessel level/density & High & High & Low & Low & Low \\
\hline Sampling & High & High & Low & Low & Low \\
\hline Heel Management & High & High & High ${ }^{\text {S }}$ & Low & Low \\
\hline PJM Restart & High & High & High & Low & Low \\
\hline $\begin{array}{l}\text { Design and Safety } \\
\text { Margin }\end{array}$ & High & High & High & Low & Low \\
\hline $\begin{array}{l}\text { CFD V\&V and } \\
\text { Comparison }\end{array}$ & High & High & Low & Medium & Medium \\
\hline $\begin{array}{l}\text { Performance and } \\
\text { Scaling }\end{array}$ & High & High & Medium & Low & Low \\
\hline High Temperature & Medium & Medium & Low & Low & High \\
\hline
\end{tabular}

${ }^{\&}$ When both Ar distribution and concentration are listed the same level, Ar distribution is more important than concentration.

$\$$ important if immobilized regimes are postulated.

Table 3: Properties important for LSIT with non-Newtonian Slurries

\begin{tabular}{|l|l|l|l|l|l|}
\hline Test Objective & Yield stress & Consistency & $\begin{array}{l}\text { Shear } \\
\text { Strength }\end{array}$ & $\begin{array}{l}\text { Density } \\
\text { difference }\end{array}$ & Particle size \\
\hline $\begin{array}{l}\text { Bottom } \\
\text { motion/accumulation }\end{array}$ & High & High & Medium & Medium & Medium \\
\hline Transfer/Pumpout & High & High & Low & Medium & Medium \\
\hline $\begin{array}{l}\text { Prototypic Integrated } \\
\text { Operations }\end{array}$ & High & High & Low & Medium & Medium \\
\hline Sparging & High & High & Low & Medium & Medium \\
\hline PJM Controllability & High & High & Low & Medium & Medium \\
\hline Vessel level/density & Low & Low & Low & High & Medium \\
\hline Sampling & High & High & Low & Medium & Medium \\
\hline Heel Management & High & High & High & Medium & Medium \\
\hline PJM Restart & Medium & Medium & High & Low & Low \\
\hline $\begin{array}{l}\text { Design and Safety } \\
\text { Margin }\end{array}$ & High & High & High & Medium & Medium \\
\hline $\begin{array}{l}\text { CFD V\&V and } \\
\text { Comparison }\end{array}$ & High & High & Low & Medium & Medium \\
\hline $\begin{array}{l}\text { Performance and } \\
\text { Scaling }\end{array}$ & High & High & Medium & Medium & Medium \\
\hline High Temperature & High & High & Low & Low & Low \\
\hline
\end{tabular}


waste slurries. For example, a property with a wide range of possible values and a large coefficient was considered highly important while a property with a narrow range of possible values might be rated low even though it had a higher coefficient. Scaling correlations for PJM tanks were preferred to those for other configurations when available, but a broad range of equations was examined in order to make the ranking judgments.

\subsection{Recommendations on Chemical versus Physical Simulants}

Chemical simulants attempt to match the chemical makeup of the waste, with or without matching the physical aspects of the waste. Physical simulants attempt to match some of the physical aspects of the waste, but do not contain the same chemical species as the waste. There are also simulants that have characteristics of both.

Chemical simulants can be prepared by matching chemical species present in the waste, by matching chemical compounds present in the waste, or by co-precipitation of the chemical compounds by processes that match the processes to which the waste is subject. For such testing, chemical simulants would typically be also required to match physical properties of the waste.

Clay slurries possess chemical effects although they are categorized as physical simulants because they match properties such as yield stress and shear strength. Physical simulants could also be composed of non-chemically matched minerals having particle sizes and densities representative of the waste.

Physical simulants are adequate for most testing of bottom motion and solids accumulation. Simulants need to cover the property ranges expected in the WTP. If performing testing with non-Newtonian fluids and using a physical simulant, the simulant needs to match both yield stress and shear strength of actual waste or be conservative. The simulant needs to be comparable on solids concentration. Properties such as particle shape, breadth of the particle size distribution, ionic strength, $\mathrm{pH}$, and particle surface charges can affect the bottom motion and accumulation of particulate solids, and should be considered in developing the simulant.

Physical simulants are adequate for the majority of testing of pump outs and transfers. The simulants need to cover property ranges expected in the WTP. If using a Newtonian fluid and testing for salt precipitation in the transfer line, WTP needs to use concentrated salt solution. If using non-Newtonian fluids, WTP needs to match yield stress and shear strength of actual waste or be conservative. The simulant needs to be comparable on solids concentration. The addition of cohesive and adhesive particles should be considered when developing the simulant, as these particles could affect the ability of a simulant to plug a transfer system.

Physical simulants are adequate for most testing of PJM controllability and prototypic integrated operations. The simulants need to cover the property ranges expected in WTP. Confirmation tests with chemical simulants during the prototypic integrated test would be valuable.

Physical simulants are adequate for the majority of sparger testing in the LSIT program. Simulants need to cover property ranges expected in WTP. If interested in foaming, slurry air entrainment (swelling), or carryover to the off-gas system, LSIT needs to use chemical simulants. If performing testing with non-Newtonian fluids and using a physical simulant, the simulant needs to be comparable to actual waste in terms of both solids concentration and non-Newtonian rheological properties simultaneously. 
Physical simulants are adequate for testing the sampling system with Newtonian and nonNewtonian fluids. A statistically defensible number of different compounds should be used in the simulant. The simulants need to cover the property ranges expected in WTP.

Physical simulants are adequate for most testing of level/density instrument accuracy. Simulants need to provide variations of fluid density with respect to time and position in the vessel. Chemical simulants may be necessary if testing to simulate specific chemical phenomena (e.g., foaming or plugging) that could influence instrument accuracy.

Chemical or physical simulants could be used for testing heel management. WTP needs to match yield stress and shear strength of actual waste, or be conservative. When matching yield stress and shear strength, the solids concentration needs to be comparable to actual waste. Chemical simulants should be used in some testing, since they could match more of the waste properties that are not reflected in yield stress and shear strength. If process chemistry, such as nitric acid addition, is part of LSIT, WTP needs to use chemically matched simulants to actual waste. If simulants are needed to represent long-term settled solids in WTP, chemical simulants are recommended.

Chemical or physical simulants could be used for testing PJM restart and design and safety margin. WTP needs simulants to match both yield stress and shear strength of actual waste, or be conservative. When matching yield stress and shear strength, the solids concentration needs to be comparable to expected actual waste levels. Chemical simulants could match more of the waste properties that are not reflected in yield stress and shear strength. If simulants are needed to represent long-term settled solids in WTP, chemical simulants are recommended.

Physical simulants are adequate for the $C F D V \& V$ testing and the $C F D$ comparison testing. The simulants need to cover the ranges of properties that are expected in the WTP and identified in this document. The CFD calculations need to match the properties of the simulants used in the testing.

If additional test objectives are added in order to simulate unit operations that perform chemical processes, a chemical simulant should be used.

\subsection{Ranges for Important Simulant Properties}

This section outlines the properties that matter to PJM mixing in the WTP. The expected range of the properties is reviewed and the influence of the property on mixing performance is discussed.

Table 4 contains the recommended ranges for Performance Testing and Scaling and Limits of Performance testing. The Performance Testing and Scaling values are based on the conservative WTP operating envelope, both before and after caustic leaching. Limits of Performance testing will base simulants off of the ranges investigated during Performance Testing and Scaling, with ranges of some parameters expanded to challenge the mixing in PJM-mixed vessels. 
SRNL-STI-2012-00062

Revision 0

Table 4: Summary of simulant property ranges recommended for LSIT

\begin{tabular}{|c|c|c|}
\hline & Performance Testing and Scaling & Limits of Performance Testing \\
\hline \multicolumn{3}{|c|}{ Newtonian Test Objectives } \\
\hline Archimedes Number & $10^{-7}$ to $6.7 \times 10^{3}$ & $10^{-7}$ to $>6.7 \times 10^{3}$ \\
\hline$\mu_{L}$ & 1 to $15 \mathrm{cP}$ & $1 \mathrm{cP}$, confirm at $15 \mathrm{cP}^{\star}$ \\
\hline$\rho_{L}$ & 1. to $1.46 \mathrm{~g} / \mathrm{mL}$ & $1 \mathrm{~g} / \mathrm{mL}$, confirm at $1.46 \mathrm{~g} / \mathrm{mL}$ \\
\hline$\rho_{S}^{\dagger}$ & $2.2-11.4 \mathrm{~g} / \mathrm{mL}$ & $2.2-11.4 \mathrm{~g} / \mathrm{mL}$ \\
\hline UDS concentration & nearly 0 to $10 \mathrm{wt} \%$ & $>10 \%$ \\
\hline Shear strength & up to $200 \mathrm{~Pa}$ & $200 \mathrm{~Pa}$ up to $2000 \mathrm{~Pa}$ \\
\hline \multicolumn{3}{|c|}{ Non-Newtonian Test Objectives } \\
\hline$\tau_{Y S}$ & 6 to $30 \mathrm{~Pa}$ & 1 to $6 \mathrm{~Pa}, 30$ to $40 \mathrm{~Pa}$ \\
\hline$\eta$ & 1 to $30 \mathrm{cP}$ & 1 to $30 \mathrm{cP}^{*}$ \\
\hline$\rho_{S}-\rho_{L}^{\dagger}$ & 1.2 to $10.4 \mathrm{~g} / \mathrm{cm}^{3}$ & 1.2 to $10.4 \mathrm{~g} / \mathrm{cm}^{3}$ \\
\hline$d_{p}^{\ddagger}$ & $0.2-700 \mu \mathrm{m}^{\wedge}$ & $0.2->700 \mu \mathrm{m}^{\#}$ \\
\hline Shear strength & up to $200 \mathrm{~Pa}$ & $200 \mathrm{~Pa}$ up to $2000 \mathrm{~Pa}$ \\
\hline
\end{tabular}

"test to failure at selected densities

- limits testing will transition into non-Newtonian rheology, with yield stress $>1 \mathrm{~Pa}$.

${ }^{\dagger}$ solid density for primary particles

${ }^{*}$ Consistency may increase as yield stress is increased

* use a range of particle sizes

minimum particle may actually be less than $0.2 \mu \mathrm{m}$

"for lower yield stress testing, increase particle size of spikes above $700 \mu \mathrm{m}$ up to the maximum determined during Newtonian testing.

\subsection{Conclusions}

This report satisfies Commitment 5.2.3.1 of the DOE IP for DNFSB Recommendation 2010-2: physical properties important to mixing and scaling. In support of waste simulant development, the following two objectives are the focus of this report:

- Assess physical and chemical properties important to the testing and development of mixing scaling relationships.

- Identify the governing properties and associated ranges for LSIT to achieve the Newtonian and non-Newtonian test objectives. This includes the properties to support testing of sampling and heel management systems.

The slurry properties that are most important to the Performance Testing and Scaling portion of WTP LSIT depend on the test objective and rheological classification of the slurry (i.e., Newtonian or non-Newtonian).

The most important properties for testing with Newtonian slurries are the Archimedes number distribution and the particle concentration. For some test objectives, the shear strength is 
important. In the testing to collect data for CFD V\&V and CFD comparison, the liquid density and liquid viscosity are important. In the high temperature testing, the liquid density and liquid viscosity are important. The Archimedes number captures effects of the particle size distribution, solid-liquid density difference, and kinematic viscosity.

The most important properties for testing with non-Newtonian slurries are the slurry yield stress, the slurry consistency, and the shear strength. The solid-liquid density difference and the particle size are important also. It is also important to match multiple properties simultaneously to achieve representative behavior.

Properties such as particle shape, particle size distribution breadth, fraction of fine particles, cohesiveness, adhesiveness, particle surface charges, liquid $\mathrm{pH}$, particle concentration, and liquid ionic strength affect the simulant properties directly and also through other physical properties such as yield stress.

The IP includes a list of characteristics that would challenge the PJM mixing and transfer systems and indicates that the assessment of simulants would include one or more of the challenging characteristics. The recommendations for properties to be adjusted during Limits of Performance testing, as related to the list of challenging characteristics, are as follows:

- Proportion of irregularly shaped particles and the degree of irregularity Recommended. Simulants should continue to include a variety of particle shapes. Spherical particles should be considered for at least a portion of the particles at the high end of the Ar distribution. A spike of flat or elongated shapes could be introduced into a baseline simulant mixture in incrementally larger proportions.

- Progressively larger particles

Recommended. For Newtonian vessels and low yield stress fluids in non-Newtonian vessels, particle size should be increased to identify the limits of performance for bottom motion/accumulation, transfer/pump out, and sampling. Heel management tests should also involve increasing the particle size.

- Progressively denser particles

Not recommended to extend beyond Performance Testing and Scaling simulant range. Simulants with a range of selected densities within the range reasonable for actual waste would be adequate for bounding the effect of increasing the particle-liquid density difference through analogous increases in particle size.

- Progressively higher shear strength of settled layers

Recommended. Testing to support PJM restart and heel management should involve increasing the shear strength of settled beds of solids to beyond the range covered by the Performance Testing and Scaling simulants.

- Progressively lower and higher yield stress and consistency for non-Newtonian simulants Recommended. Limits of performance in non-Newtonian vessels should be explored both with simulants that have less than $6 \mathrm{~Pa}$ yield stress (at $1 \mathrm{cP}$ consistency) and with simulants that have greater than $30 \mathrm{~Pa}$ yield stress and $30 \mathrm{cP}$ consistency. Limits of performance in Newtonian vessels should be explored with simulants that have greater than $1 \mathrm{~Pa}$ yield stress. 
- Progressively higher solids loading

Recommended for Newtonian mixing and heel management cases, but not recommended for non-Newtonian case beyond influence on yield stress and consistency. Heel management tests should also test increasing the quantity of settled solids in the heel.

- Progressive variation in the degree of thixotropic and rheopectic properties

Not recommended. Some of the flow curves for material in the M-12 program showed degrees of hysteresis. As acknowledged by the authors of the M-12 reports, factors other than thixotropic or rheopectic behavior could explain the hysteresis, including solids settling out of the measurement gap, evaporation of water during measurements, and sample degassing during measurements. The magnitude of the observed hysteresis was not large enough to be significant to WTP.

\subsection{Future Work}

The focus of this report is the definition of waste simulant physical properties important to mixing for WTP Performance Testing and Scaling and Limits of Performance testing portions of the LSIT. This document has been written to fulfill IP Commitment 5.2.3.1. ${ }^{3}$ Future work includes the simulant development, production, and verification for the LSIT in support of IP Commitment 5.2.3.2.

\subsection{References}

${ }^{1}$ P. S. Winokur, "Pulse Jet Mixing and the Waste Treatment and Immobilization Plant," Defense Nuclear Facilities Safety Board Recommendation 2010-2, December 17, 2010.

${ }^{2}$ T. Campbell, "Integrated Pulse Jet Mixed Vessel Design and Control Strategy," 24590-WTPRPT-ENG-10-001, Rev. 1, October 27, 2011.

3 "Department of Energy Plan to Address Waste Treatment and Immobilization Plant Vessel Mixing Issues," Implementation Plan for Defense Nuclear Safety Board Recommendation 2010-2, November 10, 2011.

${ }^{4}$ P. A. Meyer, J. A. Bamberger, C. W. Enderlin, J. A. Fort, B. E. Wells, S. K. Sundaram, P. A. Scott, M. J. Minette, G. L. Smith, C. A/ Burns, M. S. Greenwood, G. P. Morgen, E. B. K. Baer, S. F. Snyder, M. White, G. F. Piepel, B. G. Amidan, and A. Heredia-Langner, "Pulse Jet Mixing Tests With Noncohesive Solids," PNNL-18098, WTP-RPT-182, Rev. 0, May 2009.

${ }^{5}$ B. E. Wells, J. L. Huckaby, J. M. Tingey, D. E. Kurath, S. K. Cooley, R. C. Daniel, L. A. Mahoney, C. A. Burns, K. K. Anderson, Y. Onishi and E. C. Buck, "Hanford Waste Physical and Rheological Properties: Data and Gaps," PNNL-20646, EMSP-RPT-006, Rev. 0, August 2011.

${ }^{6}$ P. A. Gauglitz, B. E. Wells, J. A. Fort and P. A. Meyer, "An Approach to Understanding Cohesive Slurry Settling, Mobilization, and Hydrogen Gas Retention in Pulsed Jet Mixed Vessels," PNNL-17707, WTP-RPT-177, Rev. 0, May 2009.

${ }^{7}$ B. E. Wells, M. A. Knight, E. C. Buck, S. K. Cooley, R. C. Daniel, L. A. Mahoney, P. A. Meyer, A. P. Poloski, J. M. Tingey, W. S. Callaway III, G. A. Cooke, M. E. Johnson, M. G. Thien, D. J. 
Washenfelder, J. J. Davis, M. N. Hall, G. L. Smith, S. L. Thomson and Y. Onishi, "Estimate of Hanford Waste Insoluble Solid Particle Size and Density Distribution," PNWD-3824, WTPRPT-153, Rev. 0, February 2007.

${ }^{8}$ A. P. Poloskị, J. M. Tingey, B. E. Wells, L. A. Mahoney, M. N. Hall, G. L. Smith, S. L. Thomson, M. E. Johnson, M. A. Knight, J. E. Meacham, M. J. Thien, J. J. Davis and Y. Onishi, "Estimate of Hanford Waste Rheology and Settling Behavior," PNNL-16857, WTP-RPT-154, Rev. 0, 2007.

${ }^{9}$ R. Gimpel, Slurry Property Ranges in Non-Newtonian Pretreatment Vessels at WTP," 24590WTP-RPT-PET-10-014, Rev. 2, 6/23/2010.

${ }^{10}$ R. Claghorn, "Basis of Design,” 24590-WTP-DB-ENG-01-001, Rev. 1Q, August 4, 2011.

${ }^{11}$ J. W. Olson, "ICD 19 - Interface Control Document for Waste Feed," 24590-WTP-ICD-MG01-019, Rev. 5, August 10, 2011.

${ }^{12}$ J. Mauss, "Determination of Mixing Requirement for Pulse-Jet-Mixed Vessels in the Waste Treatment Plant," 24590-WTO-ES-PET-08-002, Rev. 2, June 28, 2010.

${ }^{13}$ P. S. Sundar, "Guideline for Simulant Development, Approval, Validation, and Documentation," 24590-WTP-GPG-RTD-004, Rev. 2, 12/08/2011.

${ }^{14}$ K. P. Lee, B.E. Wells, P.A. Gauglitz, and R.A. Sexton, "Waste Feed Delivery Mixing and Sampling Program Simulant Definition for Tank Farm Performance Testing," RPP-PLAN51625, Rev. 0, March 20, 2012.

${ }^{15}$ CRESP Review Team Letter Report 7 - PJM Vessels, July 1, 2010.

${ }^{16}$ R.S. Disselkamp, "Hanford Waste Mineralogy Reference Report,” RPP-RPT-46618, Rev. 1, June 2010.

${ }^{17}$ R. Hansen, "Request for Technology Development for CFD (Computational Fluid Dynamics V\&V (Verification and Validation) Testing," 24590-WTP-RTD-RT-11-0007, Rev. 1, March 26, 2012.

${ }^{18}$ C. E. Schilling, "Physical Properties of Hanford Metal Waste," ORNL-724, June 29, 1950.

${ }^{19}$ R. B. Bird, R. C. Armstrong, O. Hassager, Dynamics of Polymeric Liquids, Vol. 1, Fluid Mechanics, John Wiley \& Sons, New York, 1977.

${ }^{20}$ J. A. Bamberger, P. A. Meyer, J. R. Bontha, C. W. Enderlin, D. A. Wilson, A. P. Poloski, J. A. Fort, S. T. Yokuda, H. D. Smith, F. Nigl, M. A. Friedrich, D. E .Kurath, G. L. Smith, J. M. Bates, and M. A. Gerber. "Technical Basis for Testing Scaled Pulse Jet Mixing Systems for Non-Newtonian Slurries," PNWD-3551, WTP-RPT-113, Rev. 0, 2005.

${ }^{21}$ C. W. Macosko, Rheology; Principles, Measurements, and Applications, Wiley-VCH, 1994.

${ }^{22}$ L. A. Snow, E. C. Buck, A. J. Casella, J. V. Crum, R. C. Daniel, K .Draper, M. K. Edwards, S. K. Fiskum, L. K. Jagoda,E. D. Jenson, A. E. Kozelisky, P. J. MacFarlan, R. A. Peterson and R. G. Swoboda, "Characterization and Testing for PUREX Cladding Waste Sludge (Group 3) and REDOX Cladding Waste Sludge (Group 4) Actual Waste Composites," PNNL-18054, WTPRPT-167, Rev. 0, February 2009.

${ }^{23}$ R. Clift, J. R. Grace and M. E. Weber, "Bubbles, Drops, and Particles," Academic Press, Inc., 1978.

${ }^{24}$ K. Rietema, The Dynamics of Fine Powders, Elsievier Applied Sciences, 1991.

${ }^{25}$ J. N. Tilton, "Fluid and Particle Dynamics," in Perry's Chemical Engineers' Handbook, D. W. Green, R. H. Perry, eds., 8th Edition, McGraw-Hill, 2008. 
${ }^{26}$ A. Haider and O. Levenspiel, "Drag Coefficient and Terminal Velocity of Spherical and Nonspherical Particles," Powder Technology, 58, pp. 63 - 70, 1989.

${ }^{27}$ R. P. Chhabra, L. Agarwal and N. K. Sinha, "Drag on non-spherical particles: an evaluation of available methods," Powder Technology, 101, pp. 288 - 295, 1999.

${ }^{28}$ G. H. Ganser, "A rational approach to drag prediction of spherical and nonspherical particles," Powder Technology, 77, pp. 143 - 152, 1993.

${ }^{29}$ E. Loth, "Drag of non-spherical solid particles of regular and irregular shape," Powder Technology, 182, pp. 342-353, 2008.

${ }^{30}$ E. Rabinovich and H. Kalman, "Incipient motion of individual particles in horizontal particlefluid systems: A. Experimental Analysis," Powder Technology, 192, pp. 318-325, 2009.

${ }^{31}$ H. Kalman, A. Satran, D. Meir, and E. Rabinovich, "Pickup (critical) velocity of particles," Powder Technology, 160, pp. 103-113, 2005.

${ }^{32}$ R. B. Thorpe and P, Stevenson, "Suspension of Particles from the Bottom of Pipes and Stirred Tanks by Gassed and Ungassed Flows," Canadian Journal of Chemical Engineering, 81, pp. 351-359, 2003.

${ }^{33}$ K. S. Hayden, K. Park, and J. S. Curtis, "Effect of particle characteristics on particle pickup velocity," Powder Technology, 131, pp. 7-14, 2003.

${ }^{34}$ S. M. Barnes, "HLW Sludge Simulant Qualification Data Package," CCN 21493, March 23, 2010.

${ }^{35}$ D. L. Herting, "Simulant Qualification Data Package for LOAM Benchmark Testing (5 Component) - Supersedes 226286," CCN 228917, December 7, 2010.

${ }^{36}$ G. J. Lumetta, E. C. Buck, R. C. Daniel, K. Draper, M. K. Edwards, S. K. Fiskum, R. T. Hallen, L. K. Jagoda, E. D. Jenson, A. E. Kozelisky, P. J. MacFarlan, R. A. Peterson, R. W. Shimskey, S. I. Sinkov, and L. A. Snow, "Characterization, Leaching, and Filtration Testing for Bismuth Phosphate Sludge (Group 1) and Bismuth Phosphate Saltcake (Group 2) Actual Waste Composites," PNNL-17992, WTP-RPT-166, Rev. 0, February 2009.

${ }^{37}$ M. K. Edwards, J. M. Billing, D. L. Blanchard, E. C. Buck, A. J. Casella, A. M. Casella, J. V. Crum, R. C. Daniel, K. E. Draper, S. K. Fiskum, L. K. Jagoda, E. D. Jenson, A. E. Kozelisky, P. J. MacFarlan, R. A. Peterson, R. W. Shimskey, L. A. Snow, and R. G. Swoboda, "Characterization, Leaching, and Filtration Testing for Tributyl Phosphate (TBP, Group 7) Actual Waste Composites," PNNL-18119, WTP-RPT-169, Rev. 0, March 2009.

${ }^{38}$ S. K. Fiskum, J. M. Billing, E. C. Buck, J. V. Crum, R. C. Daniel, K. E. Draper, M. K. Edwards, A. E. Kozelisky, P. J. MacFarlan, R. A. Peterson, and R. W. Shimskey, "Characterization, Leaching, and Filtration Testing of Ferrocyanide Tank Sludge (Group 8) Actual Waste Composites," PNNL-18120, WTP-RPT-170, Rev. 0, February 2009.

${ }^{39}$ R. W. Shimskey, J. M. Billing, E. C. Buck, R. C. Daniel, K. Draper, M. K. Edwards, J. G. H. Geeting, R. T. Hallen, E. D. Jenson, A. E. Kozelisky, P. J. MacFarlan, R. A. Peterson, L. A. Snow, and R. G. Swoboda, "Filtration and Leach Testing for REDOX Sludge and S-Saltcake Actual Waste Composites," PNNL-17965, WTP-RPT-172, Rev. 0, February 2009.

${ }^{40}$ S. K. Fiskum, E. C. Buck, K. E. Draper, R. C. Daniel, M. K. Edwards, T. L. Hubler, L. K. Jagoda, E. D. Jenson, A. E. Kozelisky, G. J. Lumetta, P. J. MacFarlan, B. K. McNamara, R. A. Peterson, S. I. Sinkov, L. A. Snow and R. G. Swoboda, "Characterization and Leach Testing for REDOX Sludge and S-Saltcake Actual Waste Sample Composites," WTP-RPT-157, Rev. 0, July 2008. 
${ }^{41}$ W. L. Kuhn, D. R. Rector, M. J. Minette, S. D. Rassat, C. W. Enderlin, J. A. Bamberger, G. B. Josephson, B. E. Wells, S. Banerjee, and G. B. Wallis, "Large Scale Integrated Testing Technical Scaling Basis,” WTP-RPT-215, Draft, April 2012.

42 “Autosampling System Standard Tip Needle Assembly," WWG-0105469-M2-3010481-01, Rev. 10, 2/29/12.

${ }^{43}$ S. M. Barnes, "FLUENT Newtonian Model Verification and Validation Simulant Development Basis and Initial Simulant Approach,” 24590-WTP-RPT-RT-12-001, Rev. 0, April 6, 2012. 


\section{A. Appendix A: Waste Chemistry and Chemistry of Simulants}

Chemical composition is a significant property of Hanford waste slurries. Aqueous properties change during pretreatment. Caustic and oxidative leaching, coupled with washing and crossflow ultrafiltration, have associated changes in the $\mathrm{pH}$ and overall ionic strength. While these changes in aqueous phase properties often do not produce large changes in liquid viscosity or density, they can have more significant impacts on slurry properties through their interaction with the surface characteristics of the particles.

Most of the insoluble material in the Hanford tanks was formed by precipitation. Much of the material is amorphous (soft forms), but some of the material has crystallized over time into identifiable mineralogical forms (hard forms). Insoluble compounds of different elements have different properties including particle density and shape, but also including the characteristics of the exposed surfaces. Some waste particles were not formed by caustic precipitation, such as a portion of the waste contained in several tanks that originated in the Plutonium Finishing Plant. ${ }^{15}$

\section{A.1 Colloidal Properties}

Inorganic chemical particles formed by precipitation contain a significant fraction of colloidal material $(0.01$ to $1 \mu \mathrm{m})$. The interparticle forces are an important factor influencing the behavior of colloidal solids. Interparticle forces include surface electrostatic forces, induced dipole forces, and van der Waals forces. These forces become more important when the particle size is in the colloidal size range.

The isoelectric point, i.e.p., of a particle surrounded by a liquid corresponds to the $\mathrm{pH}$ where the number of positively charged surface sites equals the number of negatively charged surface sites, i.e., zero net surface potential. The electrostatic repulsive force, that normally tends to prevent small particles from agglomerating together, is minimized at the i.e.p. The range of i.e.p. for oxides and hydroxides of common elements is at least $2<\mathrm{pH}<12 .{ }^{44}$ Electrostatic repulsive forces between like particles diminish as the liquid $\mathrm{pH}$ moves toward the i.e.p. Electrokinetic experiments measure a potential in the double layer (the surrounding counterions) called the zeta potential. This measurement gives a lower bound for surface charge and helps in the determination of the i.e.p. Yield stress often reaches its maximum value when the system is near the net i.e.p. of the assembled particles. Visual changes have been observed during the precipitation of SRS waste simulants as the $\mathrm{pH}$ passes through the neutral region. Measured rheology during acidification has also showed a maximum in yield stress passing through the neutral region.

The extent to which the particle surfaces interact electrostatically is modified by both the ionic strength and the $\mathrm{pH}$ of the surrounding liquid. Increasing ionic strength shields more of the surface charges from nearby particles, while $\mathrm{pH}$ changes the net charge of the surface itself.

Ionic strength, $\mathrm{pH}$, zeta potential, and isoelectric point are all quantities that help to describe the behavior of a slurry of colloidal solids at microscopic scale. These four quantities impact macroscopic slurry physical properties such as the yield stress, consistency, viscosity, particle size, adhesiveness, and shear strength that have been established to be significant in Section 2 . Ionic strength and $\mathrm{pH}$ change during waste mobilization and transfer to WTP and during pre- 
treatment activities such as caustic leaching of aluminum and washing in the UFP vessels. The zeta potential also changes during these processing steps due to changes in the composition of solid particle surfaces, the particle size, the $\mathrm{pH}$, and the ionic strength.

\section{A.2 Colloidal solids in flowing fluids}

In dilute systems, such as Newtonian WTP waste slurries, relative motion of the liquid past the particle surface distorts the counter-ion charge cloud around a particle and produces additional stresses (the primary electro-viscous effect). In effect, the velocity field attempts to sweep the counter-ions near the particle surface back into the bulk liquid phase. In non-dilute systems the particles tend to interact with each other as well as with the flowing liquid. Two electrostatically stabilized particles approaching each other behave differently from two inert particles. Collisions are "soft" rather than "hard". Shear-induced flocculation is possible (this was postulated as one explanation for an increased fraction of larger particles in some systems following caustic leaching). ${ }^{36,39}$

During flow, repulsive forces tend to keep particles farther apart than in uncharged particle systems. This results in energy dissipation, and the observed viscosity becomes larger. This energy dissipation is known as the secondary electro-viscous effect. Electrostatic forces are independent of shear rate, and their influence is greater at low shear rates (less competition) than at high shear rates. This leads to shear thinning, and ultimately to yield stresses.

A simulant could incorporate representative ionic strength liquid, particle surface charge, and PSD to more closely match electro-viscous effects and determine the significance of the electro viscous effects to PJM energy dissipation and mixing.

\section{A.3 Cohesive Characteristics of Slurries}

All liquids and solids are cohesive to some extent. Cohesion and adhesion are similar thermodynamic concepts, defined as either a work term or a Gibbs energy associated with creating new free surface area. ${ }^{45}$ Cohesion and adhesion as defined thermodynamically can be either microscopic or macroscopic scale quantities. Cohesive work creates a surface from within a homogeneous material by subdividing it, while adhesive work creates a surface where there formerly was a phase boundary, e.g. the surface of contact between a fluid and the wall confining it. Cohesion and adhesion at the molecular scale are related to the macroscopic scale phenomena of surface tensions and interfacial tensions, that is, forces involved in changing surface area or the spreading of one material on another. The cohesive and adhesive behavior of macroscopic scale slurries is derived from the cumulative effect of the surface forces described in A.1 (summed over all sizes, compositions, etc.) coupled with the aqueous phase properties.

For a slurry, cohesive forces increase resistance to motion. However, cohesion is not equivalent to yield stress; some fluids have high cohesive strengths but exhibit no yield stress. Cohesiveness can also give rise to solid-like behavior. For example, partial recovery from deformation, or strain, has been observed in SRS simulants once the applied stress is removed. The addition of solids to a liquid can increase the cohesiveness of the slurry relative to the solid-free liquid. For a given composition, finer solids have a larger impact on cohesion because of their greater surface area per unit mass. The magnitude of slurry cohesiveness can impact yield stress, shear strength, critical shear stress for erosion, etc. A change in cohesiveness is not expected to impact all of the 
affected properties by the same amount in different systems. Slurry cohesiveness is difficult to measure directly.

Slurry cohesiveness will depend on the particle size distribution, solid mass fraction, solid phase composition, and liquid phase composition for the reasons outlined above. Potential methods for representing cohesiveness in a waste simulant involve matching some of the following aspects of the waste: chemical compounds, particle sizes, surface charges, and ionic strength and $\mathrm{pH}$ of the liquid phase. The goal would be to match yield stress, consistency, and shear strength with a simulant that also is comparable in UDS concentration. By preparing a non-Newtonian slurry with cohesive particles, there is a lower risk of missing an effect that is not directly manifested in rheology.

\section{A.4 Adhesive Characteristics of Slurries}

Cohesive slurries may also be adhesive, that is exhibit significant interaction with surrounding surfaces. At SRS, three of the eight batches processed thus far through DWPF exhibited some degree of adhesive behavior in waste both prior to and during waste processing. ${ }^{46}$ In one case, an adhesive slurry caused an approximately quarter-inch thick coating of slurry on equipment internals that was resistant to removal. In other cases, adhesive slurries at neutral to basic $\mathrm{pH}$ caused coil fouling in equipment, where sludge adhered to coils and filled the narrow gaps between tubes. Tank farm samples of caustic slurries of these sludge batches tended to stick to the stainless steel sample containers when the sludge was removed for testing in the SRNL Shielded Cells. Other DWPF batches were relatively free flowing. Rheological properties of all of the DWPF sludge batches were similar. The observed behavior indicates that phenomena not captured in the yield stress and consistency produced effects that were visible during sludge handling and processing.

Similarities between some wastes at Hanford and SRS would suggest that adhesive slurries could be encountered at some point during WTP processing. When that occurs, it can potentially interfere with some operations in PJM mixed vessels. Literature studies indicate that particle shape and surface roughness play a part in the adhesiveness of particles toward surfaces. ${ }^{47,48,49}$ However, there is currently no technical basis to underpin forecasting when adhesion may occur, what the degree of adhesion might be, or what factors affect the onset or extent of adhesion.

\section{A.5 Foaming, air entrainment, and gas retention (effects of biphylic particles)}

Agglomerates of precipitated inorganic chemical species made up of compounds of different elements have the ability to form biphylic particles. ${ }^{50}$ These particles can behave similarly to surfactant chemicals (polar head/nonpolar tail). Non-Newtonian tanks in WTP will have air spargers, which would provide a method of introducing air bubbles into the vessel contents. Foaming may occur, as was reported during the PEP tests, which used chemical simulants. ${ }^{51}$

Small bubbles in a yield stress/strength medium have insufficient buoyant force to rise through the medium and be released. Accumulation of bubbles becomes a bigger issue as the yield stress increases. When gas molecules are generated in a settled solid bed, they may diffuse out, or migrate to other locations to nucleate and grow bubbles, but the bubbles may be constrained by the surrounding bed of settled solids and unable to rise. The cohesiveness of the settled solid bed is important to gas retention because a growing bubble will attempt to displace the particles 
around it, and the cohesiveness of the bed works in opposition to the growing bubble. The yield strength of samples of different bed materials is one quantitative measure of the relative cohesiveness of different settled beds. The density of the bed material is also important, since mass per unit height contributes to the force that a rising bubble must overcome to push upwards through the settled solids.

Biphylic particles are important to gas retention as well. These particles preferentially reside at the gas-slurry interface instead of in the bulk slurry. The presence of one or more layers of biphylic particles around a bubble increases the drag force which can lead to the formation of a gas-in-slurry emulsion. This occurred during the early processing of the third DWPF sludge batch, but was mitigated by an increase in the acid added during processing. Mixing was not able to cause gas release in this waste slurry.

A previous analysis of PJM-mixed vessels concluded that mixing systems that establish full bottom motion and displacement of particles would adequately release gas. ${ }^{52}$ Thus, testing for on-bottom motion will be used rather than direct testing of gas retention and release. Simulants need to primarily replicate the shear strength of a settled bed, the bulk average density, and the depth of a settled bed release. Testing of foaming and air entrainment is not explicit within the LSIT scope, ${ }^{2}$ but such simulant characteristics may be important to PJM controllability and integrated sparger operation testing. Anti-foaming agents have already been developed and tested for use in WTP.

\section{A.6 References for Appendix A}

${ }^{44}$ G. A. Parks, "The isoelectric points of solid oxides, solid hydroxides, and aqueous hydroxocomplex systems," Chem. Rev., 65, pp. 177-198, (1965).

${ }^{45}$ P. C. Hiemenz, Principles of Colloid and Surface Chemistry, $2^{\text {nd }}$ ed., Marcel Dekker, Inc., New York, 1986.

${ }^{46}$ D. C. Koopman, "Factors Potentially Influencing the Tackiness of DWPF Streams," WSRCTR-2000-00239, Rev. 0, Savannah River Site, 2000.

${ }^{47}$ Q. Li, V. Rudolph, and W. Peukert, "London-van der Waals adhesiveness of rough particles," Powder Technology, 161, pp. 248-255, 2006.

${ }^{48}$ K. K. Lam and J. M. Newton, "Influence of particle size on the adhesion behaviour of powders, after application of an initial press-on force," Powder Technology, 73, pp. 117-125, 1992.

${ }^{49}$ A. J. Matchett and B. Bland, "The adhesion of wet particles to walls in a model trough," Powder Technology, 65, pp. 177-186, 1991.

${ }^{50}$ S. K. Bindal, A. D. Nikolev, D. T. Wasan, D. P. Lambert, and D. C. Koopman, "Foaming in Simulated Radioactive Waste," Environ. Sci. Technol., 35, pp. 3941-3947, (2001).

${ }^{51}$ D. E. Kurath, P. W. Eslinger, S. M. Barnes, R. L. Aaberg, B. D. Hanson, J. L. Huckaby, E. C. Golovich, P. M. Aker, M. J. Minette, J. M. Billing, S. D. Rassat, C. E. Guzman-Leong, D. L. Baldwin, P. S. Sundar, C. F. Brown, M. L Kimura, B. M. Rapko, G. J. Josephson, J. G. H. Geeting, S. K. Sundaram, L. A. Mahoney, J. J. Toth, G. J. Sevigny, R. P. Pires, P. P. Schonewill, S. T. Yokuda, A. J. Casella, B. E. Wells, R. C. Daniel, E. B. K. Baer, J. R. Bontha and O. P. Bredt,"Pretreatment Engineering Platform Phase 1 Final Test Report," PNNL18894,WTP-RPT-197, Rev 0, December 2009. 
SRNL-STI-2012-00062

Revision 0

${ }^{52}$ J. L. Meehan and D. J, Sherwood, "M3 - Gas Release in Newtonian Pulse-Jet Mixer (PJM) Mixed Vessels,” 24590-WTP-RPT-PET-10-007, Rev.0, 2/27/2010. 